\title{
A recent overview on the synthesis of 1,4,5-trisubstituted 1,2,3-triazoles
}

\author{
Pezhman Shiri ${ }^{*}{ }^{1,2}$, Ali Mohammad Amani ${ }^{* 1,2}$ and Thomas Mayer-Gall ${ }^{3,4}$
}

Review

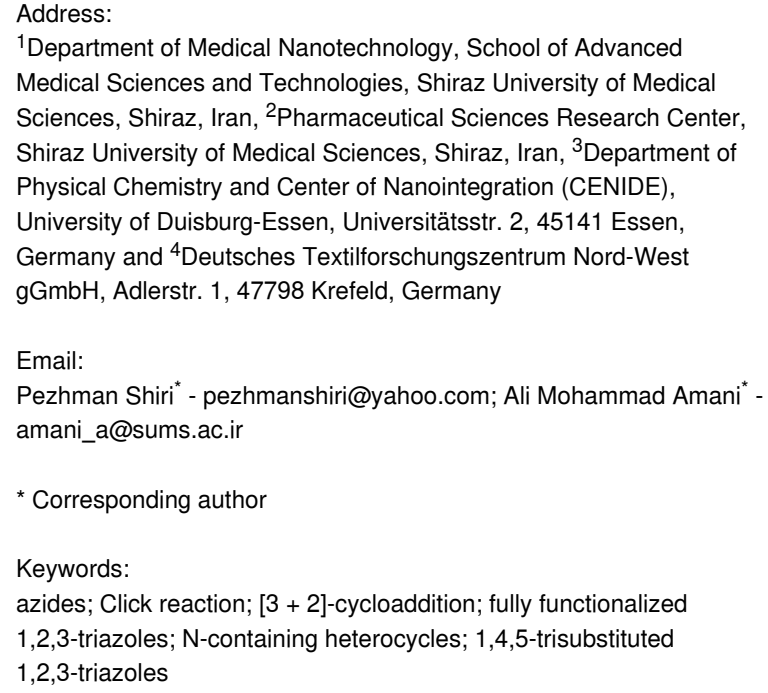

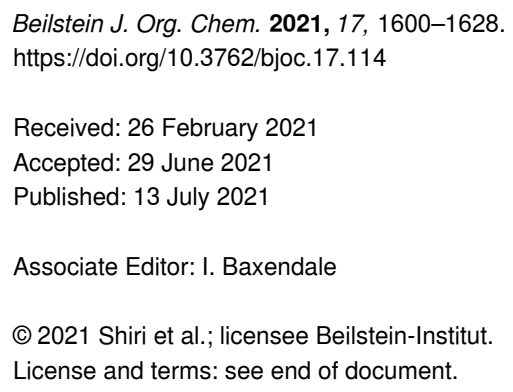

\section{Abstract}

Diverse strategies for the efficient and attractive synthesis of a wide variety of relevant 1,4,5-trisubstituted 1,2,3-triazole molecules are reported. The synthesis of this category of diverse fully functionalized 1,2,3-triazoles has become a necessary and unique research subject in modern synthetic organic key transformations in academia, pharmacy, and industry. The current review aims to cover a wide literature survey of numerous synthetic strategies. Recent reports (2017-2021) in the field of 1,4,5-trisubstituted 1,2,3triazoles are emphasized in this current review.

\section{Introduction}

A high number of N-heterocycles [1-4] are identified, and this number is increasing very quickly [5-8]. Among them, the small heterocyclic ring of the 1,2,3-triazole is present in a broad variety of compounds with not only biological but also industrial significance [9-11]. It possesses a cyclic scaffold with carbon and three nitrogen elements in the ring [12-15]. An immense versatility of biological properties is possessed by 1,2,3-triazole heterocyclic systems, and many strategies are screened for the synthesis of these rings $[16,17]$. Notably, triazole rings exhibit various medicinal applications, such as usages as anticancer [18] anti-HIV [19], antimalarial [20], antiplasmodial [21], and antibacterial agents [1,22]. Some significant triazole derivatives in this context are shown in Figure 1 [8,23-27]. 


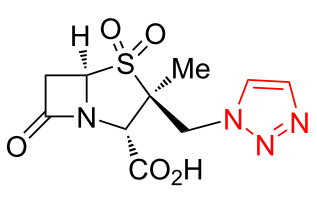

tazobactum

(antibiotic)<smiles>NC(=O)c1cn(Cc2c(F)cccc2F)nn1</smiles>

rufinamide (anticonvulsant)<smiles>NC(=O)c1nnn(Cc2cc(Cl)c(C(=O)c3ccc(Cl)cc3)c(Cl)c2)c1N</smiles>

carboxyamidotriazole

(CAl, anticancer)<smiles>[R]c1nn([Tl])c([R])c1[M]</smiles>

$\mathrm{R}^{1}$

triazole complex<smiles>OCC(c1ccccc1)n1cc(-c2ccccc2)nn1</smiles>

triazole ligand

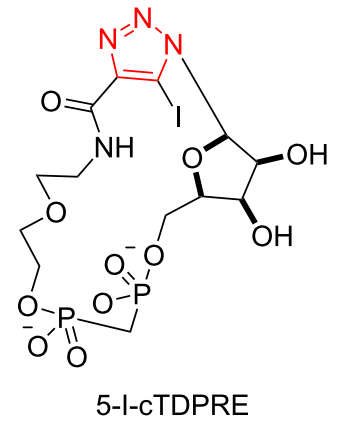

5-I-CTDPRE

Figure 1: Some significant triazole derivatives [8,23-27]

As such, there is still a demand for the expansion of ways to access new 1,2,3-triazole heterocyclic rings in rapid, efficient, and versatile ways. Triazole rings could serve as important intermediates for numerous important organic transformations [28-30]. Diverse applications of these five-membered N-heterocycles are the result of both their easy synthetic procedures and ring functionalization [9,31,32]. Typically, 1,2,3-triazole derivatives are prepared via a 1,3-dipolar cycloaddition reaction between azides and alkynes [33]. It is worth noting that the metalcatalyzed Huisgen cycloaddition reaction could provide disubstituted 1,2,3-triazoles. The selective introduction of substituents to three different positions on the 1,2,3-triazole frame can notably improve the features of the molecule. Therefore, practical and cost-effective strategies for the selective preparation of 1,4,5-trisubstituted 1,2,3-triazoles have gained much attention in triazole chemistry. Generally, two protocols for the synthesis of this type of triazole derivatives could be mentioned (metal or metal-free catalysis).

Contrary to sporadic attempts [34], there is no detailed, systematic, and updated overview covering the synthesis and mechanism aspects of 1,4,5-trisubstituted 1,2,3-triazoles. It is worth noting that several elegant reviews on the subject of substituted triazoles have been published in the last decade [34-36]. A valuable overview on earlier works on the subject of the cyclization reactions between alkynes and nitrogen sources for the synthesis of triazoles has been presented by Zeni and Neto. This review focuses on the preparation of disubstituted triazoles. However, the synthetic routes of a few 1,4,5-trisubstituted 1,2,3-triazoles have been displayed in this review [34]. In 2010 the 3,4,5-trisubstituted 1,2,4-triazoles have also been surveyed in a significant review by Fehrentz et al. This review mainly focuses on the preparation of monocyclic 3,4,5-trisubstituted 1,2,4-triazoles [37]. In 2017, different methods for the preparation of a range of 1,4,5-trisubstituted 1,2,3-triazoles through multicomponent reactions and the relevant mechanistic aspects have been surveyed by Chen, Ren, et al. [27].

The 1,3-dipolar cycloaddition reaction between azides and alkynes is the most efficient pathway for the preparation of disubstituted 1,2,3-triazole derivatives. The copper-catalyzed azide-alkyne cycloaddition (CuAAC) for the synthesis of 1,4disubstituted 1,2,3-triazole derivatives was initially discovered by the groups of Meldal and Sharpless. Then, Ru-catalyzed azide-alkyne cycloaddition (RuAAC), affording selectively 1,5disubstituted 1,2,3-triazoles, was introduced [38]. In recent years, fully substituted 1,2,3-triazole derivatives have been studied by many research groups (Scheme 1). Among an extensive range of 1,2,3-triazoles, fully decorated 1,2,3-triazoles display a sort of outstanding substance found in plenty biologically important molecules and functionalized materials. As such, the discovery of more effective strategies for the rapid preparation of these significant products is extremely desired. The regioselective synthesis of these compounds mainly includes (i) direct synthesis of fully decorated systems and (ii) postfunctionalization of disubstituted 1,2,3-triazoles. The postfunctionalization of disubstituted 1,2,3-triazole was also explained with a range of $\mathrm{C}-\mathrm{C}$ - and $\mathrm{C}-\mathrm{N}$-bond-forming reactions. A number of fully substituted 1,2,3-triazoles was provided from different compounds in moderate to high yield under mild conditions. In the last years, the exploitation of triazole rings as beneficial directing groups to produce complex triazoles has been screened. Although the postfunctionalization of disubstituted 1,2,3-triazoles may include multistep reactions for the synthesis of this kind of products, it is an easy and efficient strategy (Scheme 1).

The current review considers the synthesis of diverse 1,4,5trisubstituted 1,2,3-triazoles via metal- and metal-free catalytic routes. Synthesis and mechanism aspects of this category of 


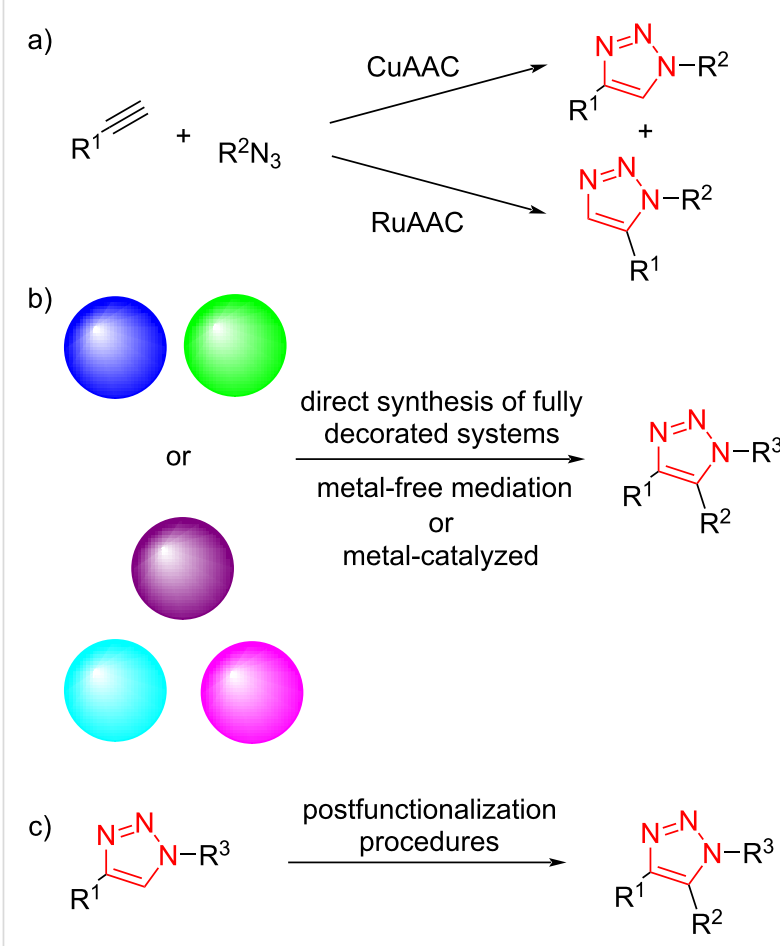

Scheme 1: A general comparison between synthetic routes for disubstituted 1,2,3-triazole derivatives and fully substituted 1,2,3-triazole derivatives.

fully functionalized triazoles are reported in detail in the current review article. We believe a precise and systematic overview on the established protocols for the synthesis of diverse fully decorated triazoles would be helpful to a wide community of researchers working in chemistry laboratories and industries. The present review is intended to describe new reports (2017 to present) concerning the synthesis of diverse fully decorated triazoles. As shown in Figure 1, 1,4,5-trisubstituted 1,2,3-triazole derivatives display a privileged class of fully decorated triazoles in Click chemistry extensively found in many biologically important compounds and functionalized frameworks. In this regard, the discovery of diverse procedures for the efficient preparation of these significant products is highly required.

\section{Review}

\section{Metal-free synthesis of fully decorated triazoles}

Developing metal-free protocols for the synthesis of triazole derivatives has been considered as growingly attractive yet challenging objectives in the environmental catalysis area. A metalfree protocol has been developed for the synthesis of 1,4,5trisubstituted 1,2,3-triazoles 3 from the reaction between $\alpha$-bromo- $\beta$-alkylacroleins and $\alpha$-bromo- $\beta$-phenylacroleins $\mathbf{1}$ and organic azides 2 in chloroform at room temperature (Scheme 2). A low to moderate yield of products was achieved using $\beta$-methyl-substituted, long-chain heptyl-substituted, and sterically hindered cyclohexyl-substituted azides. The $\alpha$-bromo- $\beta$ phenylacroleins bearing electron-donating or electron-withdrawing substituents produced the corresponding trisubstituted $\mathbf{3}$ in good to moderate yield irrespective of the nature and position of the substituent [39]

$$
\begin{aligned}
& \mathrm{R}_{1}^{\mathrm{Br}}+\mathrm{R}^{2} \mathrm{~N}^{\mathrm{CHO}} \\
& \mathrm{R}^{1}=\mathrm{H} \text {, aryl, alkyl } \\
& \mathrm{R}^{2}=\text { aryl, alkyl } \\
& \text { time }=36-72 \mathrm{~h} \\
& \text { yield }=21-99 \%
\end{aligned}
$$$$
\mathrm{R}^{2} \mathrm{~N}_{3} \stackrel{\mathrm{CHCl}_{3}, \mathrm{rt}}{\longrightarrow}
$$<smiles>[R]c1c(CO)nnn1[R]</smiles>

Scheme 2: Synthesis of formyltriazoles 3 from the treatment of $\alpha$-bromoacroleins 1 with azides 2.

The supposed reaction mechanism for the reaction is shown in Scheme 3. Initially, the presence of bromine as an electronwithdrawing substituent lowers the LUMO energy to facilitate the cycloaddition process of acrolein with organic azide. The subsequent elimination of $\mathrm{HBr}$ leads to the triazole ring [39].

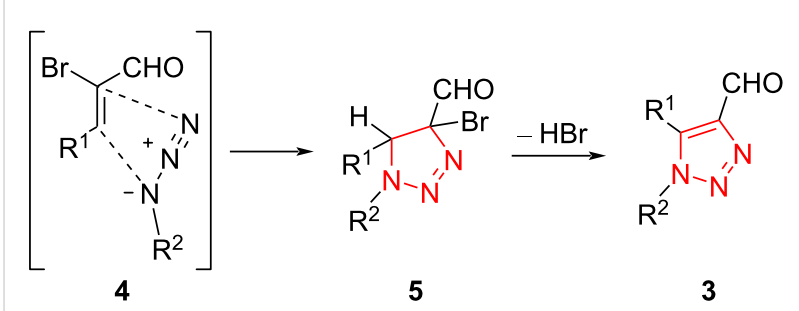

Scheme 3: A probable mechanism for the synthesis of formyltriazoles 5 from the treatment of $\alpha$-bromoacroleins $\mathbf{1}$ with azides 2 .

Another metal-free strategy to 1,4,5-trisubstituted 1,2,3-triazoles 8 was realized by regioselective reaction of aryl azides 7 with enaminones $\mathbf{6}$ in the presence of triethylamine, water, and ionic liquid (IL). This method exhibits good functional group compatibility, including using enaminones containing aliphatic and aromatic substituents as well as azide compounds containing electron-donating and -withdrawing groups on the aromatic ring. In all cases, only 4-acyl-substituted regioisomers were obtained (Scheme 4) [40].

The mechanism was also investigated by means of DFT calculations using the reaction between enaminone $\mathbf{6} \mathbf{a}$ and phenyl 


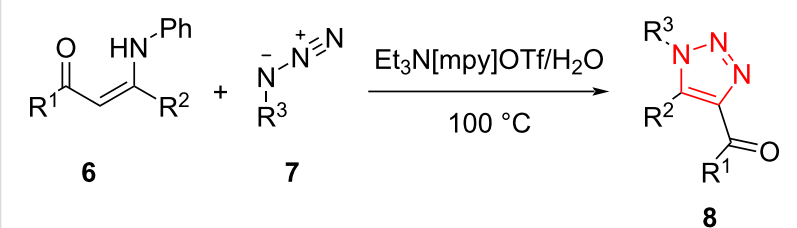

$\mathrm{R}^{1}=\mathrm{R}^{2}=\mathrm{Me}, \mathrm{Et}, \mathrm{Ph}$

$\mathrm{R}^{3}=\mathrm{Ph}, \mathrm{Bn}, 3-\mathrm{FPh}, 4-\mathrm{NO}_{2} \mathrm{Ph}, 4-\mathrm{CIPh}, 4-\mathrm{MePh}, 4-\mathrm{MeOPh}$

time $=4-6 \mathrm{~h}$

yield $=70-85 \%$

Scheme 4: Synthesis of 1,4,5-trisubstituted 1,2,3-triazoles 8 from the reaction of aryl azides 7 with enaminones 6 .

azide. TS1 and TS2 have been proposed as two transition states, which then converted to IN1 and IN2 as two possible isomers. The stable final products were achieved via a cascade reaction including the elimination of aniline (Scheme 5) [40].

A one-pot and multicomponent route to 1,4,5-trisubstituted 1,2,3-triazoles 11 containing a carboxylic ester group on the triazole ring was reported by Zhao et al. This strategy generates desired products from the reaction of readily available primary amines 10, 1,3-dicarbonyl compounds 9, and tosyl azide through a cycloaddition process in DCM as solvent and HOAc as additive at $90{ }^{\circ} \mathrm{C}$ in moderate to excellent yield (Scheme 6) [41].

As illustrated in Scheme 7, imine intermediate 12 was generated via the reaction between amine $\mathbf{1 0}$ and 1,3-dicarbonyl compound 9. Then, tautomerization of the imine intermediate produces the intermediate enamine 13. The 1,3-dipolar cycloaddition of enamine 13 with azide produces intermediate 1,2,3triazoline 14. In continuation, a ring-opening process is promoted by acetic acid to afford the intermediate 16. Afterward, triazene intermediate $\mathbf{1 7}$ was achieved by a tautomerization process. A highly decorated 1,2,3-triazole $\mathbf{1 1}$ was formed via cyclization of the intermediate $\mathbf{1 7}$ along with the loss of one molecule of $\mathrm{TsNH}_{2}$ [41].

Fully decorated 1,2,3-triazoles $\mathbf{1 9}$ containing a sulfur-based side chain have been synthesized via a cyclization of $\beta$-thiolated enaminones 18 with tosyl azide. A wide range of desired 5-thiolated 1,2,3-triazoles 19 has been prepared in good to high yield in $\mathrm{H}_{2} \mathrm{O}$ as solvent using TMEDA as a weak base, thus providing an environmentally friendly procedure that was demonstrated to be practicable also on a gram scale. A wide range of $\beta$-thiolated arylenaminones 19 containing electron-donating and -withdrawing groups were treated with azide under the standard reaction conditions. A variety of groups $\mathrm{R}^{1}$ in the phenyl ring, such as $\mathrm{Me}, \mathrm{MeO}, \mathrm{CF}_{3}, \mathrm{Br}, \mathrm{Cl}, \mathrm{F}, \mathrm{NO}_{2}, \mathrm{Et}, \mathrm{Pr}$, and $\mathrm{iBu}$ were tolerated under the reaction conditions to afford the

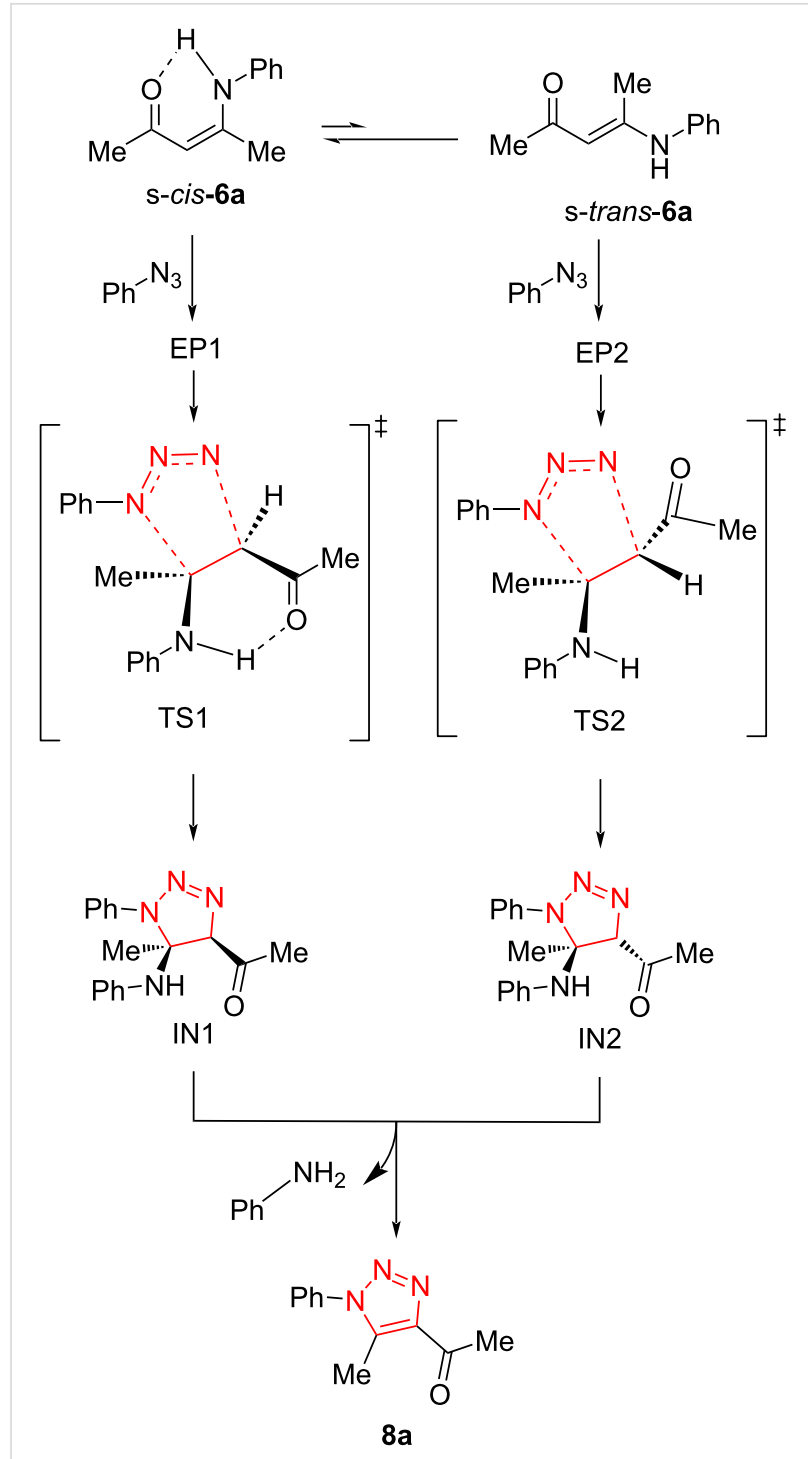

Scheme 5: Proposed mechanism for the synthesis of 1,4,5-trisubstituted 1,2,3-triazoles from the reaction of aryl azides with enaminones.

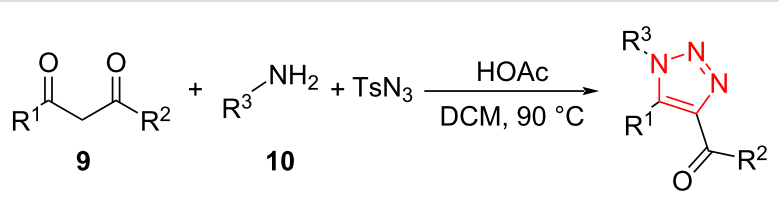

$\mathrm{R}^{1}=\mathrm{Me}, \mathrm{Et}$, cyclopropyl, Bn, Ph

11

$\mathrm{R}^{2}=\mathrm{MeO}, \mathrm{EtO}, \mathrm{iPr}$

$\mathrm{R}^{3}=\mathrm{Ph}, 2-\mathrm{MePh}, 4-\mathrm{MePh}, 2,4-\mathrm{Me}_{2} \mathrm{Ph}, 2,5-\mathrm{Me}_{2} \mathrm{Ph}$,

2,3-Me $2 \mathrm{Ph}, 2-\mathrm{MeOPh}, 4-\mathrm{MeOPh}, 3,4-\mathrm{Me}_{2} \mathrm{OPh}$,

2-EtPh, $t$-BuPh, 2-Me-4-FPh, 2-Me-3-FPh, 2-Me-5-CIPh,

2-Me-5-BrPh, 4-CIPh, 4-IPh, 2-PhPh, $n$-Pr, $n$-pentyl

time $=24 \mathrm{~h}$

yield $=34-96 \%$

Scheme 6: Synthesis of 1,4,5-trisubstituted 1,2,3-triazoles 11 from the reaction of primary amines $\mathbf{1 0}$ with 1,3-dicarbonyl compounds $\mathbf{9}$. 

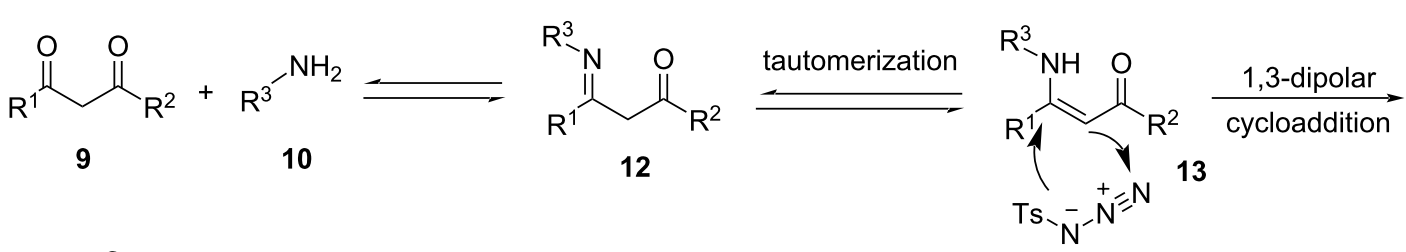

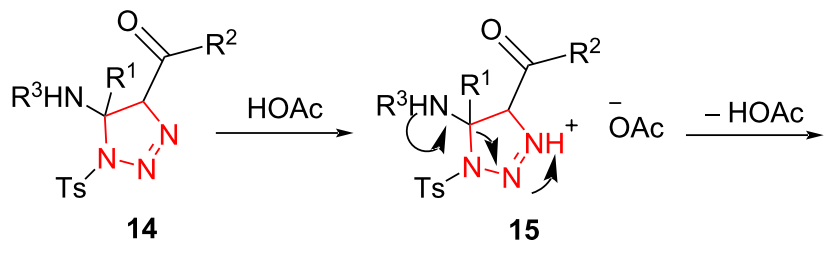

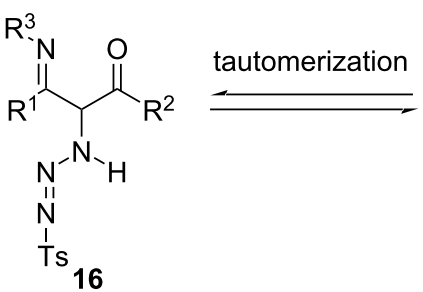

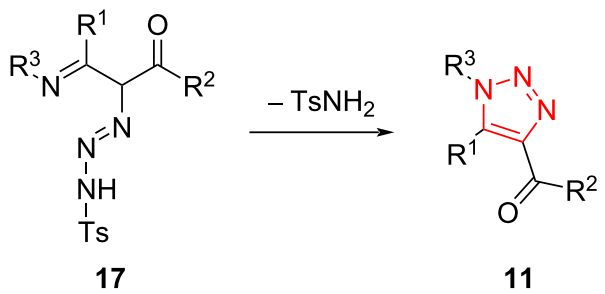

Scheme 7: The proposed mechanism for the synthesis of 1,4,5-trisubstituted 1,2,3-triazoles 11 from the reaction of primary amines 10 with 1,3-dicarbonyl compounds 9 .

desired fully substituted triazoles in good to high yield. The phenyl ring could also be replaced by naphthyl and furyl rings to give the corresponding products in good to excellent yield. Besides, aryl and alkyl groups for $\mathrm{R}^{2}$ displayed applicability in the preparation of corresponding 1,4,5-trisubstituted 1,2,3-triazoles. However, $N$-aryl products were yielded with slightly higher yield than the N-alkylated ones. Furthermore, it is notable that different alkylthio-containing starting materials, such as Et-, Pr-, and iBu-substituted thiolated enaminones, could react with azide substrate to produce corresponding triazole products in moderate yield (Scheme 8) [42].

The authors proposed a reaction mechanism in which the $\beta$-thioenaminone $\mathbf{1 8}$ tolerates deprotonation to afford anionic intermediate $\mathbf{2 1}$ through the tautomer $\mathbf{2 0}$ in the presence of a base. In the next step, the nucleophilic addition of $\mathbf{2 1}$ to the azide takes place to form intermediate $\mathbf{2 2}$, which subsequently converts to diazo-functionalized intermediate 23. Finally, the intramolecular annulation of intermediate $\mathbf{2 3}$ gives corresponding fully decorated 1,2,3-triazole $\mathbf{1 9}$ (Scheme 9) [42].

A domino coupling synthesis of fully decorated 1,2,3-triazole compounds 25 through the regioselective addition and cyclization reaction of 1,1-enediamines (EDAMs) 24 with $p$-methylbenzenesulfonyl azide in 1,4-dioxane as solvent at reflux was presented by Yan et al. Some substituted EDAMs $\left(\mathrm{R}^{1}=\mathrm{R}^{2}\right)$ were concluded to be treated with $\mathrm{TsN}_{3}$. In continuation, substituted EDAMs $\left(\mathrm{R}^{1} \neq \mathrm{R}^{2}\right)$ were also applied to check the regioselectiveness of this addition and cyclization reaction. The meth-

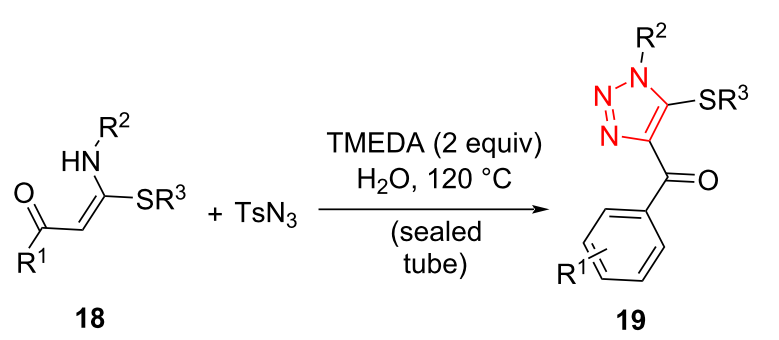

$\mathrm{R}^{1}=4-\mathrm{MePh}, \mathrm{Ph}, 3-\mathrm{MePh}, 2-\mathrm{MePh}, 4-\mathrm{MeOPh}, 3,4-\mathrm{Me}_{2} \mathrm{OPh}$, 4-FPh, 4-CIPh, 4-BrPh,

4- $\mathrm{CF}_{3} \mathrm{Ph}, 4-\mathrm{NO}_{2} \mathrm{Ph}, 4-\mathrm{MePh}$, 2-naphthyl, furanyl

$\mathrm{R}^{2}=\mathrm{Ph}, 4-\mathrm{MePh}, 3-\mathrm{MePh}, 4-\mathrm{MeOPh}, 4-\mathrm{CIPh}, \mathrm{Bn}, \mathrm{Me}$

$\mathrm{R}^{3}=\mathrm{Me}, \mathrm{Pr}, \mathrm{iBu}$

time $=6 \mathrm{~h}$

yield $=56-89 \%$

Scheme 8: Synthesis of fully decorated 1,2,3-triazoles 19 containing a sulfur-based side chain.

odology provides a simple, straightforward, and facile path to access fully decorated 1,2,3-triazoles $\mathbf{2 5}$ in moderate to good yield. Noticeably, this uncatalyzed addition and cyclization process displayed good regioselectivity (Scheme 10) [23].

The authors proposed that the reaction may proceed through the mechanism illustrated in Scheme 11. Initially, EDAM 24 is treated with an azide source and subsequently, the intermediate $\mathbf{2 6}$ is formed through 1,2-addition reaction. The intermediate $\mathbf{2 6}$ is imine-enamine-tautomerized to afford the intermediate $\mathbf{2 7}$. 

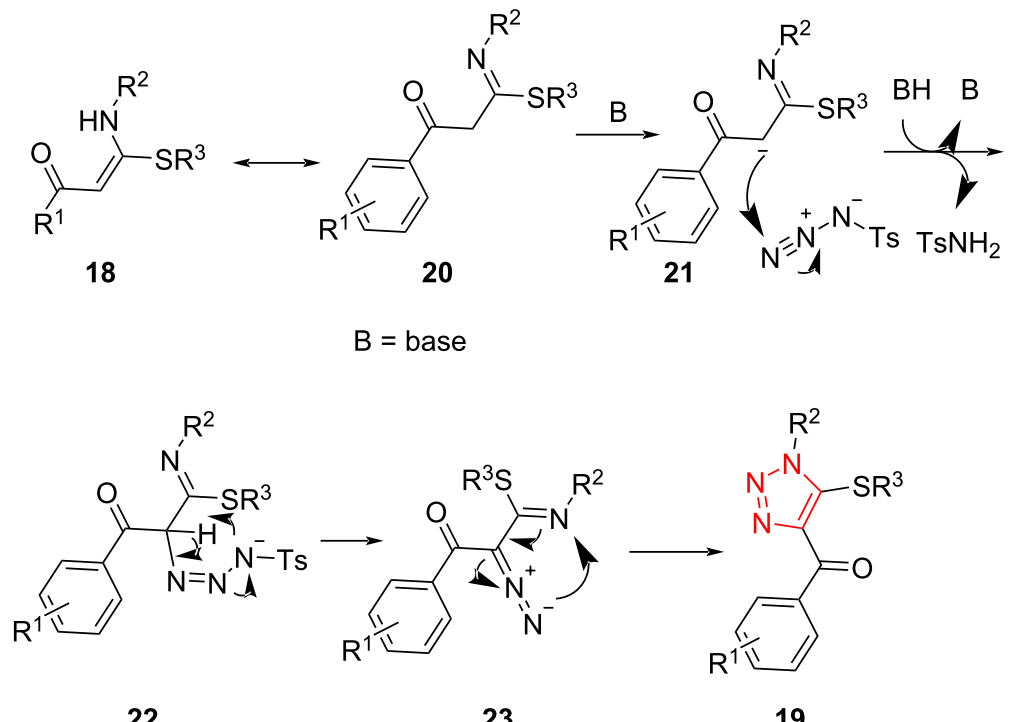

22

23

19

Scheme 9: Mechanism for the formation of fully decorated 1,2,3-triazoles 19 containing a sulfur-based side chain.<smiles>[R4]NC(=CC([R])=O)N[R4]</smiles>

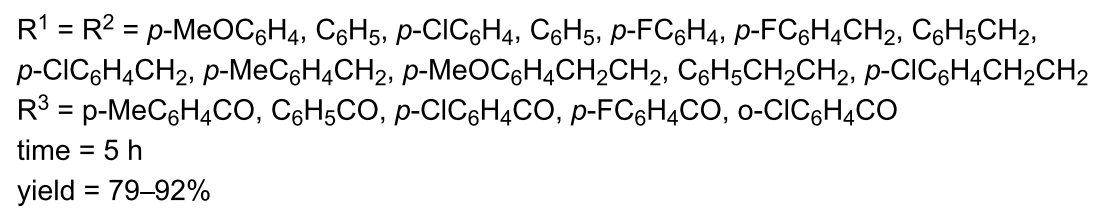

Scheme 10: Synthesis of fully decorated 1,2,3-triazole compounds 25 through the regioselective addition and cyclization reaction of EDAMs 24 with $p$-methylbenzenesulfonyl azide.

Then, the final triazole compound, as major isomer, is achieved through an intermolecular cyclization process and elimination of one unit of $\mathrm{TsNH}_{2}$ [23].

A general strategy was described for the synthesis of 1,4,5trisubstituted glycosyl-containing 1,2,3-triazole derivatives $\mathbf{3 0}$ from the reaction of glycosyl azides $\mathbf{2 8}$ with enolates of active ketones and esters 29 in the presence of DBU in DMF at $70{ }^{\circ} \mathrm{C}$ (Scheme 12) [43]. Diverse monosaccharide and disaccharide azides were successfully reacted with a variety of enolates of active ketones and esters $\mathbf{2 9}$, such as 1,3-diketones, $\beta$-ketoesters, cyclic 1,3-diketone (dimedone), and $\beta$-ketoamide, respectively, to afford desired 1,4,5-trisubstituted 1,2,3-triazoles containing glycosyl with high yield. It should be pointed out that no byproducts were recognized under optimized reac- tion conditions. In addition, a range of functional groups have been investigated, and the results exhibited that they were unaffected. Finally, it would be possible to scale up the reaction with a negligible decrease in the yield of product [43].

The synthesis of enantiomerically pure 1,4,5-trisubstituted 1,2,3-triazoles 34 via intramolecular cyclization reaction of ketones 31, $p$-nitrophenyl azide (PNA, 32) and amino esters 33 has been described by Dehaen et al. The products were often obtained in good yield and in all cases with the retention of the configuration of the stereocenter. The reaction was carried out by employing a variety of amino esters and a wide range of (hetero)aromatic and alkyl ketones. Natural products, such as $5 a$-cholestan-3-one and dihydrotestosterone, were also tolerated, affording a new strategy to modify biologically active 


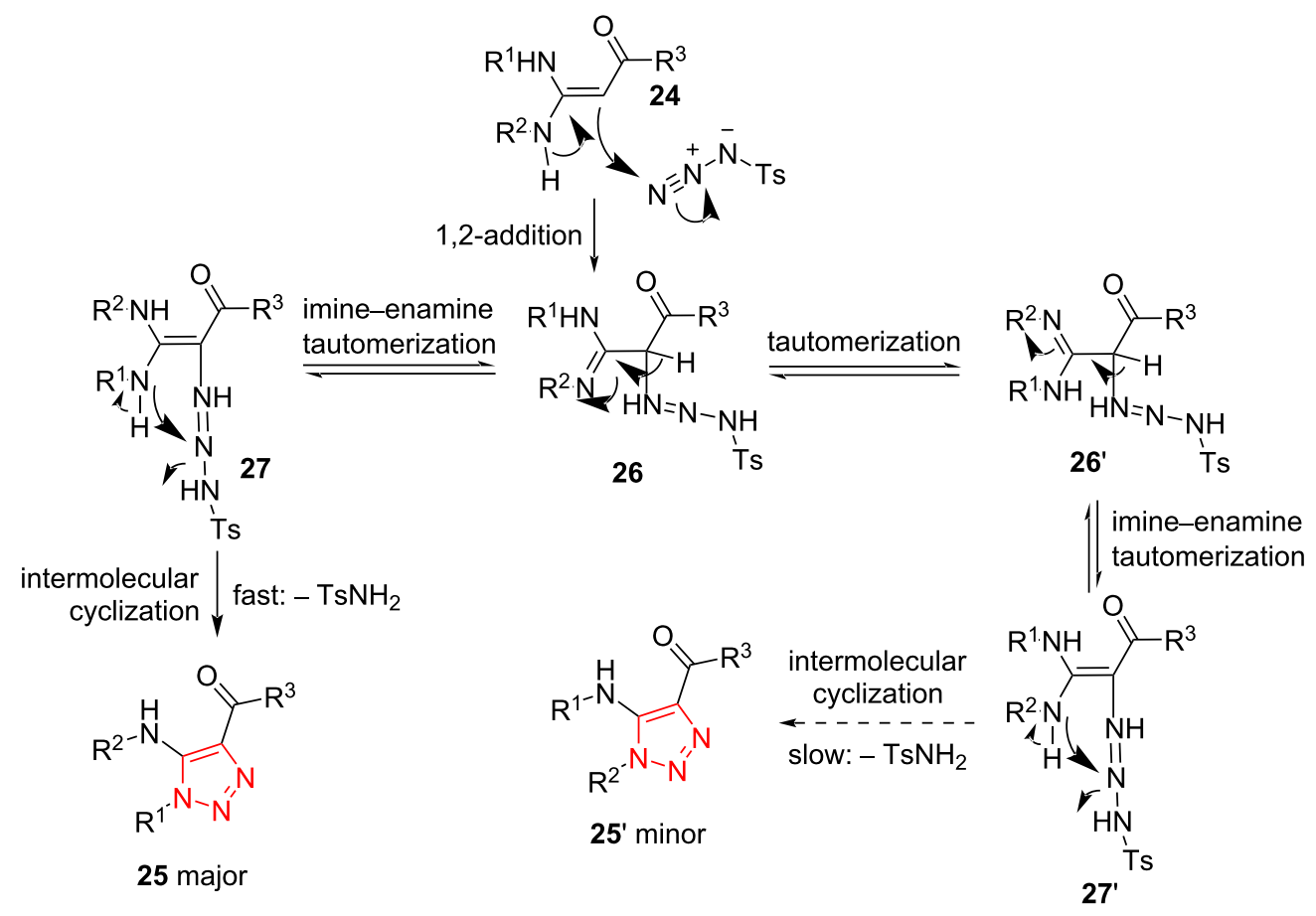

Scheme 11: A reasonable mechanism for the synthesis of fully decorated 1,2,3-triazole compounds 25 through the regioselective addition and cyclization reaction of EDAMs 24 with $p$-methylbenzenesulfonyl azide.

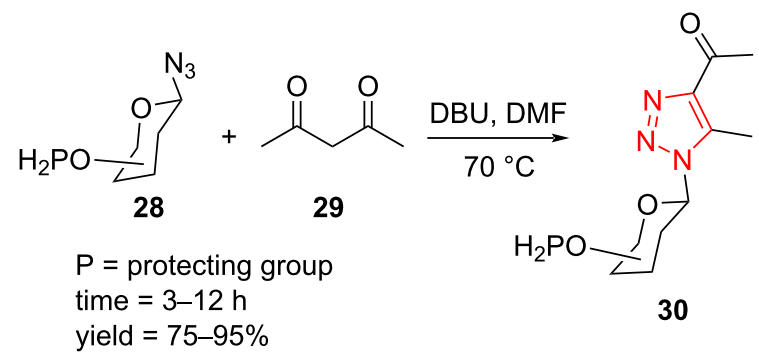

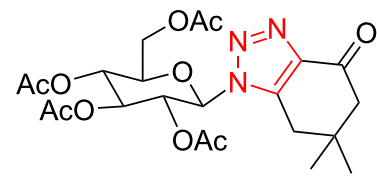

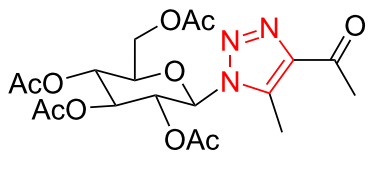

$10 \mathrm{~h}, 76 \%$

$3 \mathrm{~h}, 90 \%$

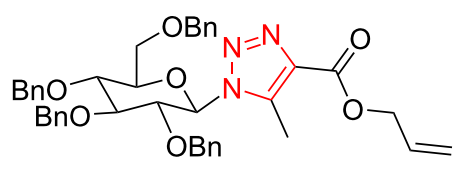

$8 \mathrm{~h}, 82 \%$

Scheme 12: Synthesis of 1,4,5-trisubstituted glycosyl-containing 1,2,3triazole derivatives $\mathbf{3 0}$ from the reaction of glycosyl azides $\mathbf{2 8}$ with enolates of active ketones and esters 29. compounds. Amino acids, such as tyrosine, L-Phe-L-Phe, glutamic acid, and serine derivatives were proceeded to extend the scope of the reaction (Scheme 13) [44].

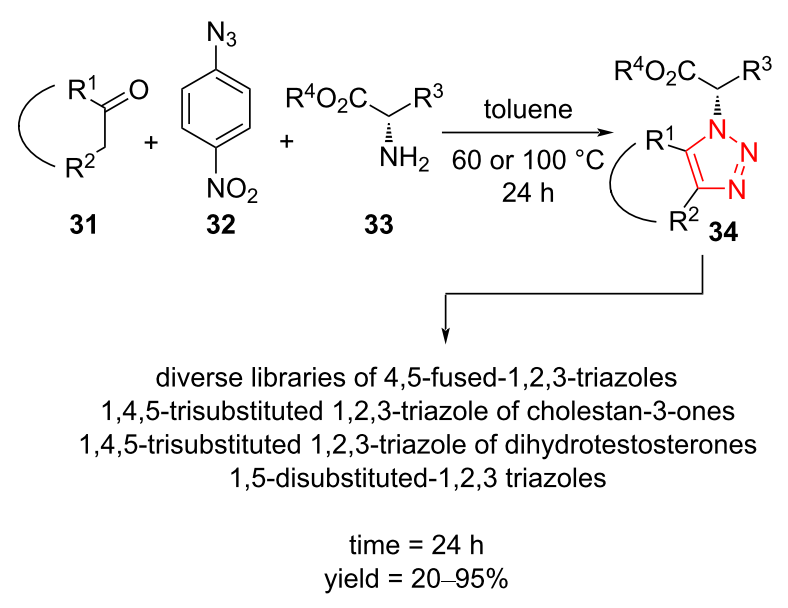

Scheme 13: Synthesis of 1,4,5-trisubstituted 1,2,3-triazoles 34 via intramolecular cyclization reaction of ketones 31 , PNA (32), and amino esters 33 .

An efficient domino three-component route has been developed for the synthesis of fully decorated 1,2,3-triazoles $\mathbf{3 8}$ bearing a sulfonyl group in position 4 . The synthesis required aldehydes 
35, amines 36, $\alpha$-diazo- $\beta$-ketosulfones $37, \mathrm{I}_{2}$, and $\mathrm{K}_{2} \mathrm{CO}_{3}$ in EtOH. The scope and limitations of the reaction were assessed using alkyl aldehydes, (hetero)aryl aldehydes, amines, and diazosulfones. Reactions of aryl aldehydes containing a range of different functional groups gave products $\mathbf{3 8}$ in very good yield. Because of the faster hydrolysis of the in situ generated imine intermediates, aromatic aldehydes containing electronwithdrawing substituents afforded no product in the reaction. It was proved that a variety of aliphatic primary amines can efficiently produce the triazole products (Scheme 14) [45].

This one-pot tandem reaction proceeds via formation of a Schiff-base 39 and subsequently 1,3-dipolar cycloaddition to produce the intermediate $\mathbf{4 2}$. Then, the intermediate $\mathbf{4 2}$ affords the final product $\mathbf{4 3}$ via an oxidative aromatization process in the presence of air or iodine (Scheme 15). To propose a precise mechanism, a cyclization reaction was carried out without molecular iodine in an inert atmosphere. No final product was observed, and only $\mathbf{4 2}$ was achieved in good yield. However, 42 was effectively transformed into the corresponding product with excellent yield in the presence of molecular iodine (Scheme 15) [45].

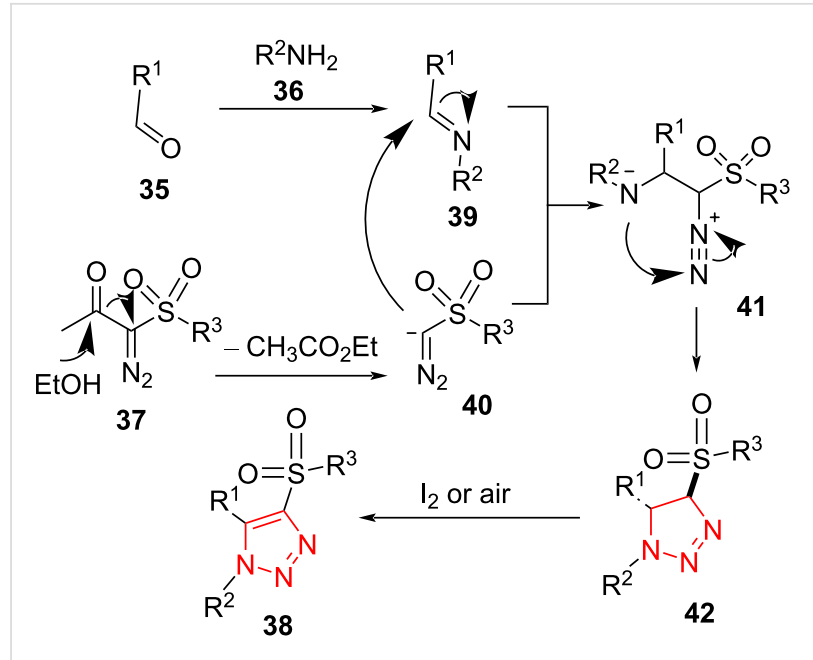

Scheme 15: A reasonable mechanism for the synthesis of fully decorated 1,2,3-triazoles $\mathbf{3 8}$ from the reaction of aldehydes $\mathbf{3 5}$, amines $\mathbf{3 6}$, and $\alpha$-diazo- $\beta$-ketosulfones 37 .

In 2020, Ramachary et al. reported the 1,3-dipolar cycloaddition of various enones $\mathbf{4 3}$ and $\mathbf{4 6}$ with less reactive vinyl/alkyl/ aryl azides $\mathbf{4 4}$ via an enolate-mediated organocatalyst. This

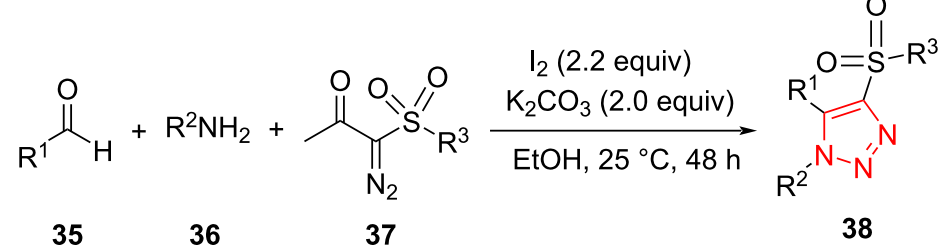

$\mathrm{R}^{1}=\mathrm{Ph}, 4-\mathrm{MeOPh}, 4-\mathrm{Me}_{2} \mathrm{NPh}$, 4-PhPh, 4-t-BuPh, 4-iPrPh, 4-BrPh, 3-MeOPh, 2-MeOPh, 3-MeO-4-HOPh, 3,4,5- $\mathrm{Me}_{3} \mathrm{OPh}$, pyrenyl, ferrocenyl, furanyl, $1 \mathrm{H}$-imidazolyl, pyridyl, quinolinyl, $\mathrm{PhCHCH}, \mathrm{CH}_{3} \mathrm{CH}_{2} \mathrm{CH}_{2} \mathrm{CHCH}$,<smiles>CC(C)(C)/C=C/C(Br)C(O)COc1ccccc1</smiles><smiles>CCCCn1nnc(S(=O)(=O)c2ccccc2)c1-c1ccc(C(C)(C)C)cc1</smiles>

$\mathrm{R}^{2}=n$-Bu, $n$-Pr, $n$-octyl, $n$-nonyl, $n$-decyl, allyl, iPr, $t$ - $\mathrm{Bu}, \mathrm{C}_{6} \mathrm{H}_{11} \mathrm{CH}_{2}$, $\mathrm{PhCH}_{2}$, 4-FPhCH$, 4-\mathrm{ClPhCH}_{2} \mathrm{CH}_{2}, \mathrm{Ph}_{2} \mathrm{CHCH}_{2}, \mathrm{Ph}_{2} \mathrm{CH}$, $(\mathrm{MeO})_{2} \mathrm{CHCH}_{2}, \mathrm{HOCH}_{2} \mathrm{CH}_{2} \mathrm{CH}_{2}, \mathrm{Et}_{2} \mathrm{NCH}_{2} \mathrm{CH}_{2}$,<smiles>CCCCC(CC)CC(C)(C)C</smiles><smiles>CC(C)(C)C1CCc2ccccc21</smiles><smiles>CC(C)(C)Cc1ccco1</smiles><smiles>CC(C)(C)CNS(=O)(=O)c1ccccc1</smiles><smiles>CC(C)(C)CCNc1ccnc2cc(Cl)ccc12</smiles>

$\mathrm{R}^{3}=4-\mathrm{MePh}, 4-\mathrm{CIPh}, 4-\mathrm{FPh}, 4-\mathrm{CF}_{3} \mathrm{Ph}, 4-\mathrm{NO}_{2} \mathrm{Ph}, \mathrm{MeCONHPh}, 2,3-\mathrm{Cl}_{2} \mathrm{Ph}$, naphthyl, $\mathrm{Me}$ time $=48 \mathrm{~h}$ yields $=41-95 \%$ 
protocol provides diverse double $\mathrm{C}$ - and $\mathrm{N}$-vinylated 1,2,3-triazole derivatives and $\mathrm{C}$-vinylated 1,2,3-triazole derivatives from azidophilic substrates and different azide derivatives. A short reaction time, good to high yield of products, high diversity, high selectivity, and ease of operation were some benefits of this methodology. The enolate reactivity with azides was compared to enamines. The best conditions were the use of a catalytic amount of DBU in DMSO at room temperature [46].

The cyclic enones $\mathbf{4 3}$ were reacted with the $\alpha$-azidostyrenes $\mathbf{4 4}$ containing groups such as $\mathrm{Cl}, \mathrm{F}$, and $\mathrm{OMe}$ to form the corre- sponding products (Scheme 16). The $o-, m^{-}$, and $p$-tolylvinyl azides facilitated a good to excellent yield of the products. The tolylvinyl azide substituted with methyl at the ortho position afforded a lower yield of the desired product. The vinyl azides containing 2-naphthyl, $\beta$-phenyl, and 1-((2-azidoallyl)oxy)-4nitrobenzenevinyl azides formed the corresponding products in high yield as well. Moreover, the alkyl-substituted cyclic enones treated successfully with azidophiles to give good yield of the corresponding double $\mathrm{C}$ - and $\mathrm{N}$-vinylated 1,2,3-triazole derivatives 45 . Then, the reaction was extended to some aryl and alkyl azides and different cyclic enones. Moreover, a

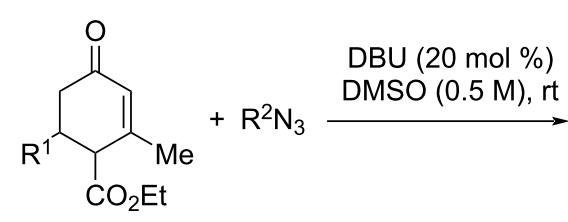

43<smiles>[R]COC(=O)C1=C([R])Cc2c(nnn2[R4])C1</smiles>

45

$\mathrm{R}^{1}=\mathrm{H}, \mathrm{Ph}, 4-\mathrm{ClPh}, 4-\mathrm{NO}_{2} \mathrm{Ph}, \mathrm{CH}_{3} \mathrm{CH}_{2}, \mathrm{PhCH}_{2} \mathrm{CH}_{2}$

$\mathrm{R}^{2}=$<smiles>[X]c1ccc(C(=C)C(C)(C)C)cc1</smiles>

$\mathrm{X}=\mathrm{H}, 4-\mathrm{Cl}, 4-\mathrm{F}, 4-\mathrm{OMe}, 4-\mathrm{Me}, 3-\mathrm{Me}, 2-\mathrm{Me}$<smiles>C=C(COc1ccccc1)C(C)(C)C</smiles>

$\mathrm{Ph}, 4-\mathrm{MePh}$, 4-MeOPh, 4-FPh, 4-BrPh, 3-BrPh, 2-BrPh, 3- $\mathrm{CF}_{3} \mathrm{Ph}, 4-\mathrm{O}_{2} \mathrm{NPh}, 3-\mathrm{O}_{2} \mathrm{NPh}, 2-\mathrm{O}_{2} \mathrm{NPh}, \mathrm{PhCH}$, naphthyl

time $=0.5-7.5 \mathrm{~h}$

yield $=36-95 \%$

$\underset{46}{\mathrm{CO}_{2} \mathrm{Me}} \frac{\mathrm{CO}_{2} \mathrm{Me}}{\mathrm{Me}}$<smiles>[R1]n1nnc(/C=C/COCC)c1C</smiles><smiles>C1CNC2CCCN=C2C1</smiles>

DBHU

$\mathrm{R}^{1}=\mathrm{Ph}, 4-\mathrm{MePh}, 4-\mathrm{MeOPh}$, naphthyl, 4-CIPh, 3-CIPh, 2-CIPh, 4-NCPh, Ph

time $=1-3.5 \mathrm{~h}$

yield $=40-88 \%$

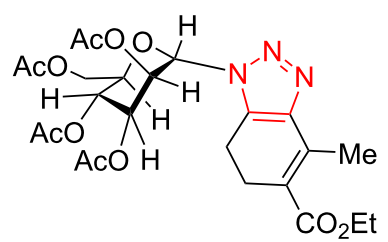

$(+)-6(69 \%, 3 \mathrm{~h})$

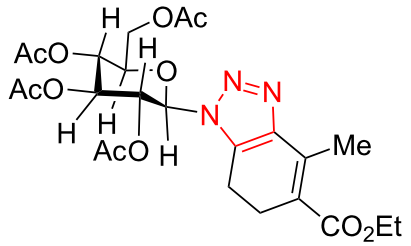

$(-)-6(72 \%, 3 \mathrm{~h})$ 
variety of vinyl, alkyl, and aryl azides were also applicable in the reaction. In continuation of the study, various alkyl- and aryl-substituted unmodified cyclic enones were explored, and the result was a moderate to good yield of the corresponding products. The reaction was performed well using alkyl-substituted cyclic enone. Finally, acyclic enone $\mathbf{4 6}$ reacted with aryl and vinyl azides to afford a moderate to high yield of the triazole products (Scheme 16) [46].

A simple one-pot two-stage strategy for the synthesis of disubstituted 4-chloro-, 4-bromo-, and 4-iodo-1,2,3-triazoles $\mathbf{5 0}$ from the reaction of the corresponding nonactivated alkynes 48 with organic azides was studied by Smirnov et al. The alkynes $\mathbf{4 8}$ were subjected to the action of $\mathrm{MeMgCl}$ in THF and then, the desired aryl azides were added into the solution, followed by the addition of $N$-halosuccinimide to give chloro-, bromo-, and iodotriazoles 50 (Scheme 17) [47]. It was found that the reaction requires a strict control of the temperature in the different steps, while the nature and position of the substituents of the aryl azide do not influence the yield of the reaction. The use of aliphatic alkynes, as well as the replacement of bromine and chlorine with iodine, leads to a decrease in the yield [47].

Some research groups have utilized strain-promoted azide-alkyne cycloaddition reactions (SPAAC) on side chains to afford polymer-based prodrugs. Generally, a range of key strained cyclooctyne derivatives $\mathbf{5 2}$ could be reacted with aliphatic azides $\mathbf{5 1}$ via this strategy to give fully decorated triazoles 53 (Scheme 18a). A research group reported a novel polymer $\mathbf{5 6}$ functionalized by doxorubicin (DOX). To produce this prodrug, cyclooctyne-derivatized doxorubicin $\mathbf{5 5}$ was grafted on an azide-functionalized polymer 54. In the final step of the construction of this prodrug, the reaction between $\mathbf{5 4}$ and 55 was performed in anhydrous methanol under an argon atmosphere to construct 56. The study on the in vitro drug release showed enhanced drug release at an acidic $\mathrm{pH}$ value in comparison to a neutral $\mathrm{pH}$ value. Importantly, the amount of DOX re- quired for MCF-7 cells was decreased after the support of DOX molecules on the polymer prodrug, which resulted in reduced side effects (Scheme 18b) $[48,49]$.

\section{Cu-catalyzed synthesis of fully decorated tri- azoles}

The Cu-catalyzed regioselective cyclization of alkynes $\mathbf{5 7}$ and azides $\mathbf{5 8}$, followed by coupling with propargylic carbonates $\mathbf{5 9}$, afforded the corresponding 5-allenyl-1,2,3-triazoles $\mathbf{6 0}$ in moderate to excellent yield. The reaction was tolerant to the presence of a range of aryl-, alkyl-, and heteroaryl-substituted alkynes as well as aryl and alkyl azides. Subsequently, the scope of propargylic carbonates was further explored, altogether leading to a moderate to high yield of the products (Scheme 19) [50].

A reasonable mechanism for this cyclization/coupling reaction involves the generation of a 5-copper(I)-substituted triazolide intermediate 62, which coordinates with propargyl carbonate 59. Further insertion of the $\mathrm{C}-\mathrm{C}$ triple bond of an alkyne into the $\mathrm{Cu}$-triazole bond gives $\mathbf{6 4}$, which then undergoes syn- $\beta$ oxygen elimination to provide the target product. On the other hand, an oxidative addition and reductive elimination sequence can also generate the target product (Scheme 20) [50].

An immobilized copper complex has been found to be efficient for a practical pathway to 5-alkynyl-1,2,3-triazoles $\mathbf{6 9}$ from organic azides 67 , alkynes $\mathbf{6 6}$, and 1-bromoalkynes $\mathbf{6 8}$. To test the scope of this reaction, a number of alkyl- and (hetero)arylsubstituted alkynes as well as (alkyl)aryl azides have been used in this reaction, affording 5-alkynyl-1,2,3-triazoles 69 in good to high yield. Moreover, heteroaryl-substituted 1-bromoalkyne, $\mathrm{iPr}_{3} \mathrm{Si}$-substituted 1-bromoalkyne, and a number of alkyl-substituted 1-bromoalkynes were treated in this process to provide the corresponding products with good to high yield (Scheme 21) [51]. It is noteworthy that the immobilized copper complex has been synthesized in some steps. Initially, MCM-41 was reacted

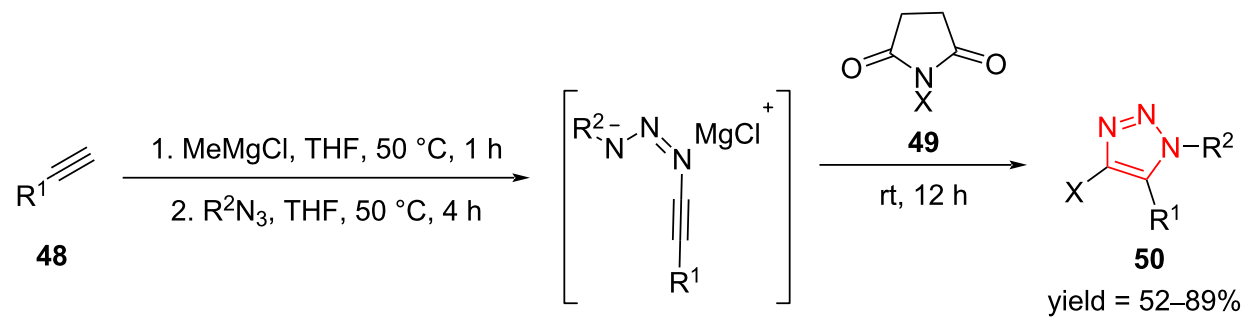

$$
\begin{array}{ll}
\mathrm{X}=\mathrm{Cl}, \mathrm{R}^{1}=n-\mathrm{Pr}, \mathrm{R}^{2}=\mathrm{Ph} & \mathrm{X}=\mathrm{Br}, \mathrm{R}^{1}=\mathrm{Ph}, \mathrm{R}^{2}=p-\mathrm{MeOPh} \\
\mathrm{X}=\mathrm{Cl}, \mathrm{R}^{2}=\mathrm{Ph}, \mathrm{R}^{2}=\mathrm{Ph} & \mathrm{X}=\mathrm{Br}, \mathrm{R}^{1}=\mathrm{Ph}, \mathrm{R}^{2}=o-\mathrm{MeOPh} \\
\mathrm{X}=\mathrm{Cl}, \mathrm{R}^{2}=t-\mathrm{Bu}, \mathrm{R}^{2}=\mathrm{Ph} &
\end{array}
$$

$\mathrm{X}=\mathrm{I}, \mathrm{R}^{1}=n-\mathrm{Pr}, \mathrm{R}^{2}=\mathrm{Ph}$

$\mathrm{X}=\mathrm{I}, \mathrm{R}^{2}=\mathrm{Ph}, \mathrm{R}^{2}=p-\mathrm{MeOPh}$

$X=I, R^{2}=P h, R^{2}=o-M e O P h$ 


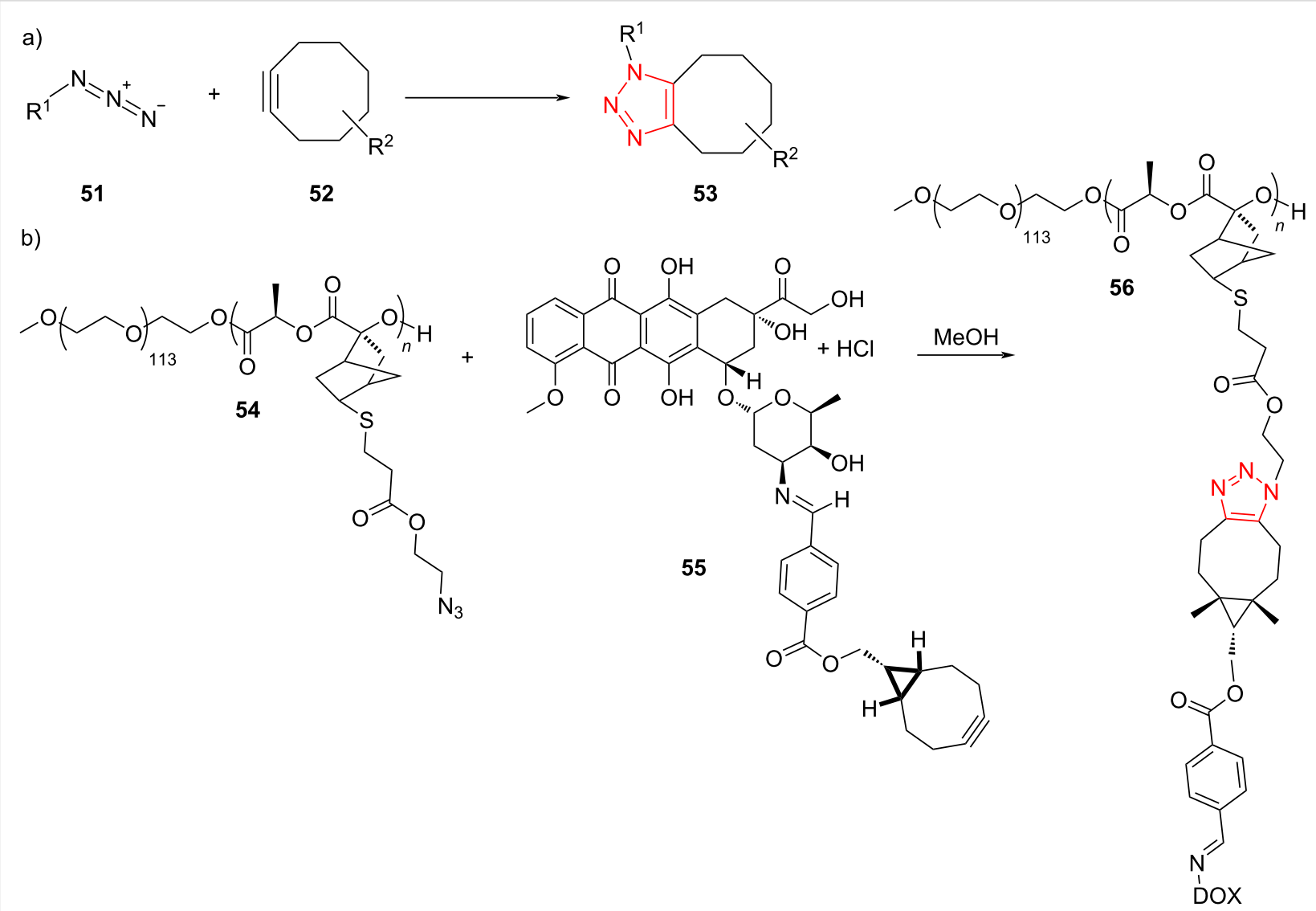

Scheme 18: a) A general route for SPAAC in polymer chemistry and b) synthesis of a novel pH-sensitive polymeric prodrug 56 via SPAAC Click chemistry.

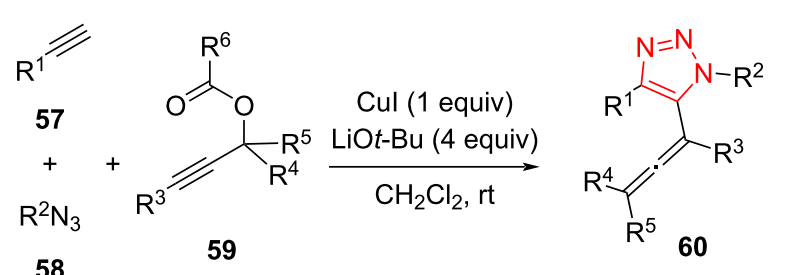

58

$\mathrm{R}^{1}=4-\mathrm{MePh}, \mathrm{Ph}, 4-n-\mathrm{BuPh}, 4-\mathrm{MeOPh}, 4-\mathrm{FPh}$, 4-CIPh, 4-BrPh, 4-CF $3 \mathrm{Ph}, 2-\mathrm{CIPh}, 3-\mathrm{CIPh}$, ferrocenyl, thiophenyl, cyclopropyl, Bu

$\mathrm{R}^{2}=\mathrm{PhCH}_{2}, 4-t-\mathrm{BuPh}, 3-\mathrm{CIPhCH}_{2}, 2-\mathrm{BrPhCH}_{2}, \mathrm{PhCH}_{2} \mathrm{CH}_{2}$, $\mathrm{Ph}, \mathrm{PhCHCHCH}_{2}$, octyl, Ts

$\mathrm{R}^{3}=\mathrm{TMS}, \mathrm{Ph}, 4-\mathrm{MeCOPh}, \mathrm{Bu}$,

$\mathrm{R}^{4}=\mathrm{R}^{5}=\mathrm{Me}, \mathrm{Et}$
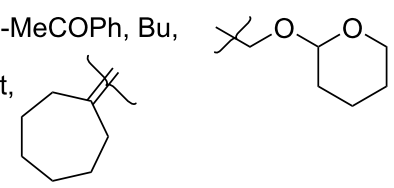

$\mathrm{R}^{6}=\mathrm{Me}$

time $=12 \mathrm{~h}$

yield $=40-99 \%$

Scheme 19: Synthesis of 5-allenyl-1,2,3-triazoles 60 by the treatment of alkynes $\mathbf{5 7}$, azides $\mathbf{5 8}$, and propargylic carbonates $\mathbf{5 9}$. with 2-(4-(chloromethyl)phenyl)ethyltrimethoxysilane in toluene at $110{ }^{\circ} \mathrm{C}$ for $24 \mathrm{~h}$. The resulting material was then treated with $\mathrm{Me}_{3} \mathrm{SiCl}$ in toluene at mild temperature to afford the chloromethyl-modified MCM-41 ( $\left.\mathrm{ClCH}_{2}-\mathrm{MCM}-41\right)$. In the next step, L-proline-modified MCM-41 (L-proline-MCM-41) was produced by the treatment of $\mathrm{ClCH}_{2}-\mathrm{MCM}-41$ with $\mathrm{N}$-Boctrans-4-hydroxy-L-proline in THF in the presence of $\mathrm{NaH}$ as base, which was then deprotected using TFA in $\mathrm{CH}_{2} \mathrm{Cl}_{2}$. In the last step, the immobilized copper complex (L-proline-MCM-41$\mathrm{CuCl}$ ) was obtained by the reaction of L-proline-MCM-41 with $\mathrm{CuCl}$ in acetone at mild temperature (Scheme 21) [51].

A possible mechanism for this reaction is shown in Scheme 22. Initially, copper(I)-substituted acetylide intermediate $\mathbf{7 0}$ is produced via the reaction of copper catalyst with the corresponding acetylide by using $\mathrm{LiO} t$-Bu. Further intermolecular $[3+2]$-cycloadditions of azide $\mathbf{6 7}$ with intermediate $\mathbf{7 0}$ affords a 5-copper(I)-substituted triazolide intermediate 71. The oxidative addition of 1-bromoalkyne $\mathbf{6 8}$ forms an alkyne-Cu(III)Br-triazole complex intermediate 72. Finally, a reductive elimination takes place to give the corresponding final product and the catalyst for the next run [51]. 


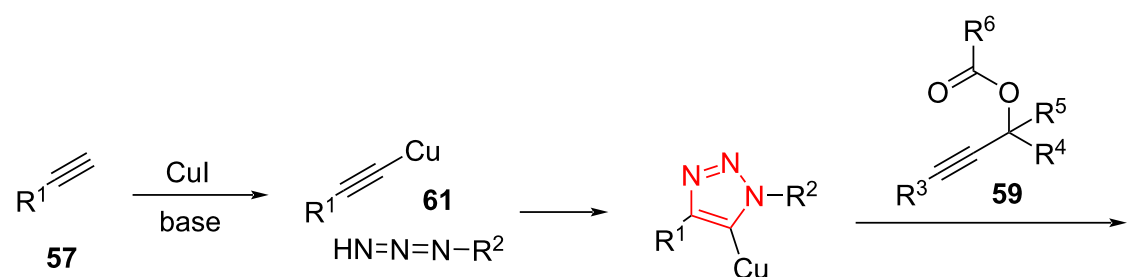

58

62

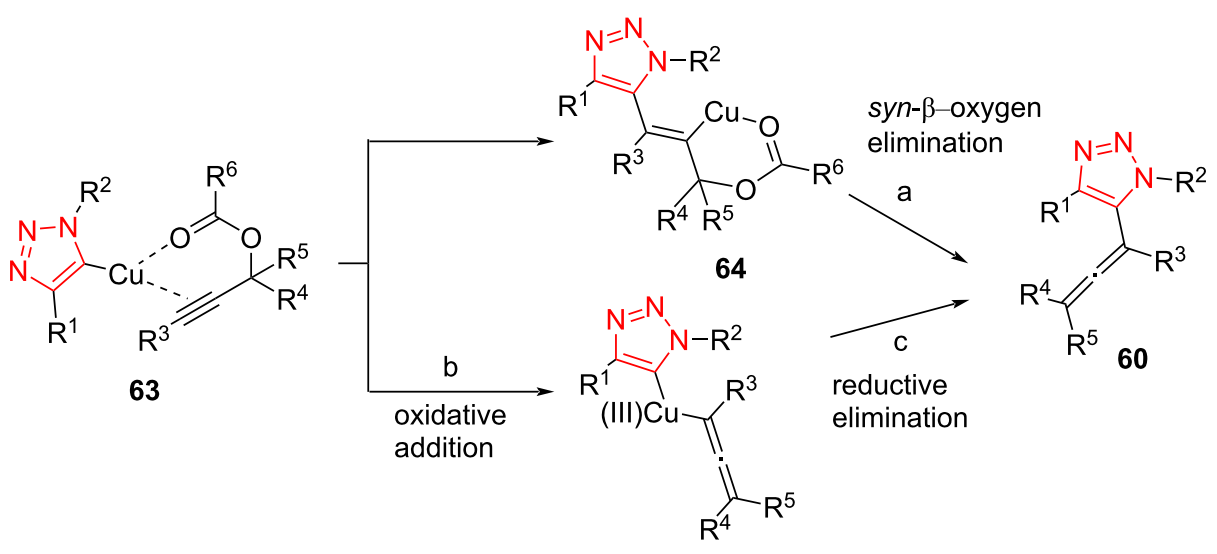

65

Scheme 20: A reasonable mechanism for the synthesis of 5-allenyl-1,2,3-triazoles $\mathbf{6 0}$ by the treatment of alkynes $\mathbf{5 7}$, azides $\mathbf{5 8}$, and propargylic carbonates 59 .

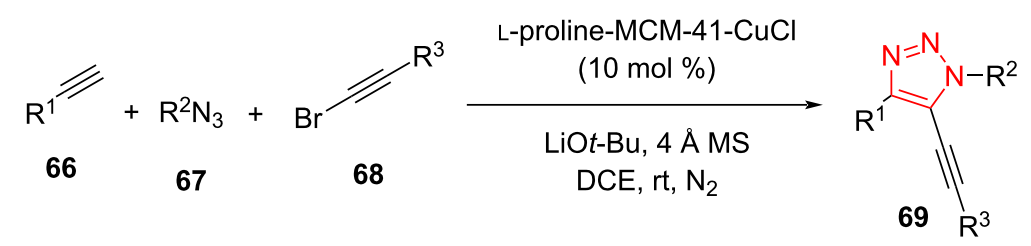

$\mathrm{R}^{1}=\mathrm{Ph}, 4-\mathrm{MeOPh}, 4-\mathrm{FPh}, 4-\mathrm{CIPh}, 4-\mathrm{F}_{3} \mathrm{CPh}, 4-\mathrm{EtPhPh}$, naphthyl, thiophenyl, $n-\mathrm{Bu}$, $\mathrm{PhCH}_{2} \mathrm{CH}_{2}, \mathrm{PhOCH}_{2}$, cyclopropyl,<smiles>CC(C)(C)C1=CCCCC1</smiles>

$\mathrm{R}^{2}=\mathrm{PhCH}_{2}, 4-\mathrm{MePhCH}_{2}, 4-\mathrm{FPhCH}_{2}, 4-\mathrm{CNPhCH}_{2}$, naphthyl, $\mathrm{PhCHCHCH}_{2}$, n-octyl,<smiles>CC(C)(C)CC(C)(C)n1ccc2ccccc21</smiles>

$\mathrm{R}^{3}=4-\mathrm{MeOPh}$, 4-MePh, 4-BrPh, thiophenyl, $n-\mathrm{C}_{6} \mathrm{H}_{13}, \mathrm{PhCH}_{2} \mathrm{CH}_{2}, \mathrm{PhCH}_{2} \mathrm{OCH}_{2}$, cyclohexyl, $\mathrm{SiiPr}_{3}$

time $=12 \mathrm{~h}$<smiles></smiles>
yield $=64-92 \%$

Scheme 21: Synthesis of 5-alkynyl-1,2,3-triazoles 69.

A tandem Click/intramolecular sulfenylation procedure for the synthesis of sulfur-cycle-fused 1,2,3-triazoles $\mathbf{7 5}$ and $\mathbf{7 7}$ was described by $\mathrm{Xu}$ et al. The reaction was performed through a $[3+2]$-cycloaddition between alkynes $\mathbf{7 3}$ and $\mathbf{7 6}$ and alkylthiotosyl azides $\mathbf{7 4}$ using MeOLi in the presence of a copper(I) cata- lyst in dioxane at room temperature. This Click/intramolecular sulfenylation reaction displayed an extensive scope, complete regioselectivity, and good to high yield of products, allowing the construction of a number of medium- and large-sized triazole-fused heterocycles $\mathbf{7 5}$ and 77. Many aliphatic, aromatic, 


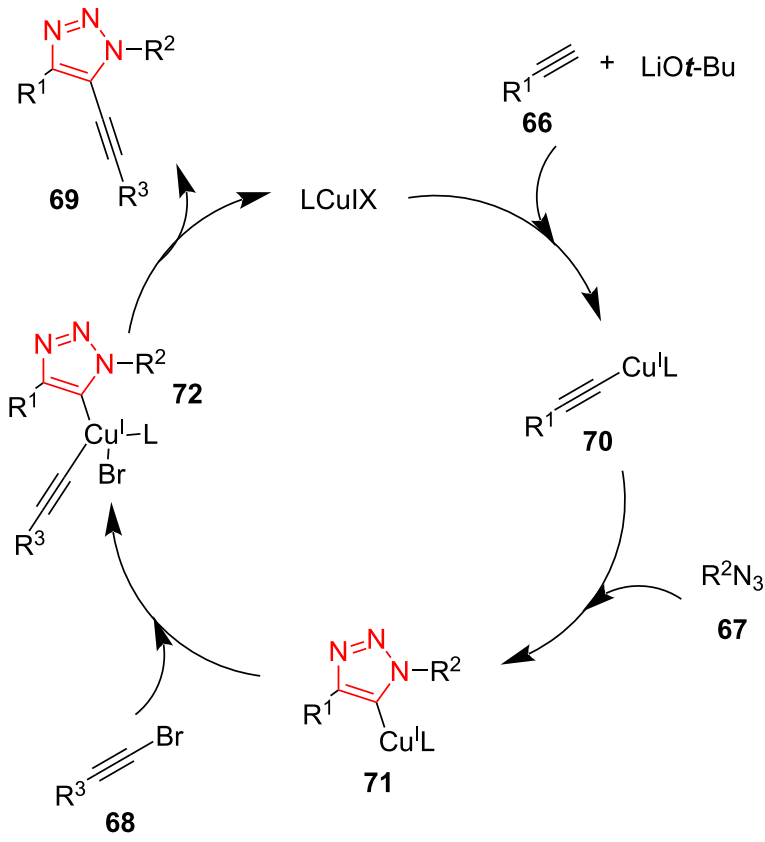

Scheme 22: A reasonable mechanism for the synthesis of 5-alkynyl1,2,3-triazoles 69

thiophenyl-, and ferrocenyl-substituted acetylenes were found to give excellent results in the reaction with aliphatic tosylthio azides 74 with different chain length $(n=1-3)$. For azides with $n=3$, the reaction was performed using alkynes bearing rather complex $\mathrm{R}^{2}$ substituents, such as tyrosine, glucose, clofibrate, vitamin $\mathrm{E}$, estrone, and oleanane triterpenes, which tolerated the reaction conditions and afforded the corresponding triazoles $\mathbf{7 7}$ fused with a six-membered sulfur-containing cycle (Scheme 23) [52].

Some reactions were performed to screen the reaction mechanism in detail. To find out if the reaction proceeds through a radical pathway, tetramethylpiperidine-1-oxyl (TEMPO) was added to the reaction. The corresponding product was obtained in high yield, which displayed that a radical pathway may not be involved. The compound $\mathbf{8 0}$ also failed to give the corresponding product under standard conditions, which exhibits that $\mathbf{8 0}$ is not an intermediate in this reaction. On the other hand, the 1,4-disubstituted 1,2,3-triazole did not convert to the corresponding product under the standard conditions, denoting that the reaction did not include the sequence of CuAAC followed by $\mathrm{C}-\mathrm{H}$ activation. According to these facts, the reaction mechanism may be as below. First, the copper(I)-substituted acetylide $\mathbf{7 8}$ was generated via the reaction of the copper source and the alkyne $\mathbf{7 3}$ or $\mathbf{7 6}$ using a base. This subsequently cyclized with the azide $\mathbf{7 3}$ to afford the triazole cuprate intermediate 79. Finally, the resulting intermediate proceeds through an oxidative addition and reductive elimination sequence to give the final product, followed by the next cycle (Scheme 24) [52].

A one-pot and multicomponent protocol for the synthesis of 5 -selanyltriazoles $\mathbf{8 5}$ from the reaction of ethynylstibanes 82, organic azides $\mathbf{8 3}$, and diaryl diselenides $\mathbf{8 4}$ using catalytic amounts of $\mathrm{CuI}$ and 1,10-phenanthroline in DMSO at $60{ }^{\circ} \mathrm{C}$ under air with good to high yield was presented by Yasuike et al. (Scheme 25). To find the scope of this strategy, diverse ethynylstibanes $\mathbf{8 2}$ containing substituents including aryl, vinyl, and alkyl were reacted with organic azides $\mathbf{8 3}$ and diaryl diselenides $\mathbf{8 4}$ to form desired products. In addition, a variety of organic azides $\mathbf{8 3}$ containing substituents such as cinnamyl, (ethoxycarbonyl)methyl, 1-naphthalenemethyl, and (phenylthio)methyl were cyclized with ethynylstibanes $\mathbf{8 2}$ and diaryl diselenides $\mathbf{8 4}$ to afford the desired triazole products. The reaction between ethynylstibane, organic azide, and a range of diaryl diselenides $\mathbf{8 4}$ including sterically hindered $o$-substituted and heterocyclic derivatives efficiently proceeded to give the desired 5-selanyl-1,2,3-triazoles 85 [53].

A possible mechanism was suggested and is displayed in Scheme 26. First, the $\mathrm{Cu}(\mathrm{I})$-catalyzed cyclization of ethynylstibane $\mathbf{8 2}$ and azide $\mathbf{8 3}$ gives the intermediate 86, which attacks the $\mathrm{Cu}(\mathrm{III})$ intermediate $\mathbf{8 7}$, formed via the reaction between diaryl diselenide $\mathbf{8 4}$ and the bimetallic complex $\left[\mathrm{L}_{2} \mathrm{Cu}\right]_{2} \mathrm{I}_{2}$. Next, the produced intermediate $\mathbf{8 8}$ undergoes a reductive elimination to achieve intermediate $\mathbf{8 9}$ with regeneration of the $\mathrm{Cu}$ complex $\left[\mathrm{L}_{2} \mathrm{Cu}\right]_{2} \mathrm{I}_{2}$. Then, nucleophilic attack of the aryl selenide anion to the antimony atom takes place to give 5-selanyltriazole 85 and $\mathrm{Ph}_{2} \mathrm{Sb}-\mathrm{SeAr}$. $\mathrm{Ph}_{2} \mathrm{Sb}-\mathrm{SeAr}$ is hydrolyzed in aqueous medium to give selenol 90 and $\mathrm{Ph}_{2} \mathrm{SbOH}$. Selenol $\mathbf{9 0}$ is oxidized in air and transformed into diselenide $\mathbf{8 4}$. Therefore, only 0.5 equiv of diaryl diselenide were necessary for the reaction as both of the two selanyl groups are used [53].

Trisubstituted triazoles 93 containing an Sb substituent at position C5 were prepared via a Cu-catalyzed [3+2]-cycloaddition reaction between several ethynylstibanes $\mathbf{9 1}$ and benzyl azide 92 using $\mathrm{CuBr}$ under air. The reaction proceeded to afford 5-stibanotriazoles 93 in good yield (Scheme 27) [54]. The 5-stibanotriazoles 93 were used as intermediates for the synthesis of 5-unsubstituted triazoles 94 in the presence of $\mathrm{HCl}(10 \%)$ in THF at $0{ }^{\circ} \mathrm{C}$. The antitumor activity of 5 -stibanotriazoles 93 as well as 5-unsubstituted triazoles $\mathbf{9 4}$ was explored using some tumor cell lines. The results exhibited that 5-stibanotriazoles $\mathbf{9 3}$ exerted a superior antitumor activity. Contrariwise, 5-unsubstituted 1,2,3-triazoles showed very low antitumor activity in comparison to 5-stibanotriazoles. Since 5-unsubstituted 1,2,3-triazoles did not display good antitumor activity in comparison to 


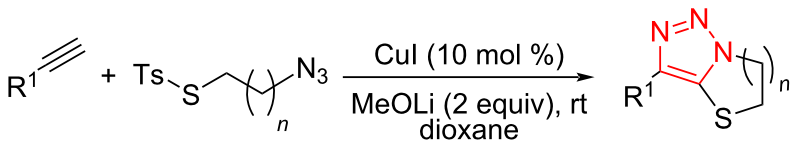

$$
\begin{aligned}
& 73 \quad \begin{array}{c}
74 \\
n=1-3
\end{array}
\end{aligned}
$$

$\mathrm{R}^{1}=\mathrm{Ph}, 4-\mathrm{MePh}$, 4-MeOPh, 4-BrPh, 4-CNPh, 4-CF 3 Ph, 4$\mathrm{CO}_{2} \mathrm{MePh}, 2-\mathrm{MePh}, 3-\mathrm{NO}_{2} \mathrm{Ph}$, naphthyl, thiophenyl, $\mathrm{PhCHCH}$, $\mathrm{PhOCH}_{2}, \mathrm{CH}_{3} \mathrm{CH}_{2} \mathrm{CH}_{2} \mathrm{CH}_{2}$, cyclopropyl,

time $=12 \mathrm{~h}$

yield $=70-93 \%$

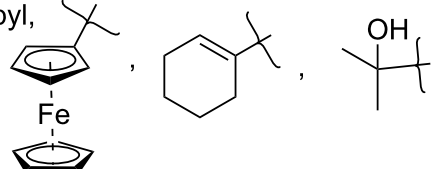

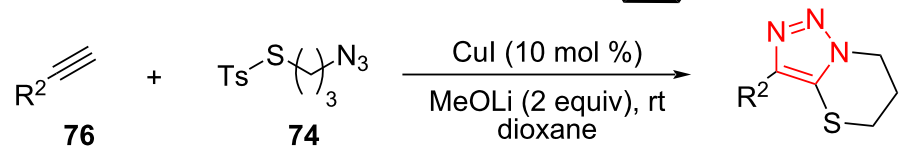<smiles>[R]=C[C@H](Cc1ccc(OCC(C)(C)C)cc1)NC(C)(C)C</smiles>

$86 \%$, from tyrosine

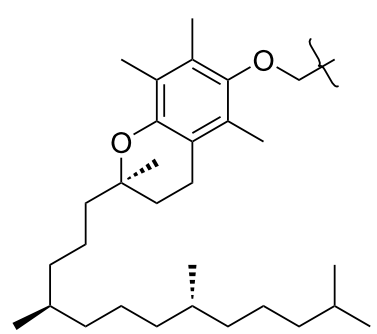

$87 \%$, from vitamin $E$

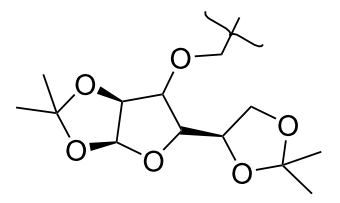

$92 \%$, from glucose

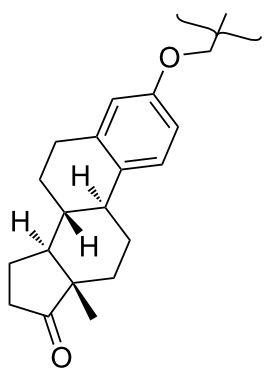

$88 \%$, from estrone
77<smiles>COC(=O)C(C)(C)Oc1ccc(C(C)(C)C)cc1</smiles>

$84 \%$, from clofibrate, lipid-lowering agent

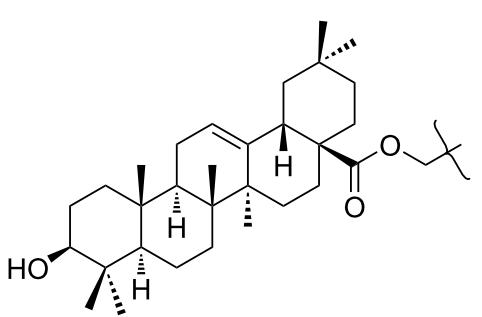

$78 \%$, from oleanane

Scheme 23: Synthesis of sulfur-cycle-fused 1,2,3-triazoles 75 and 77.

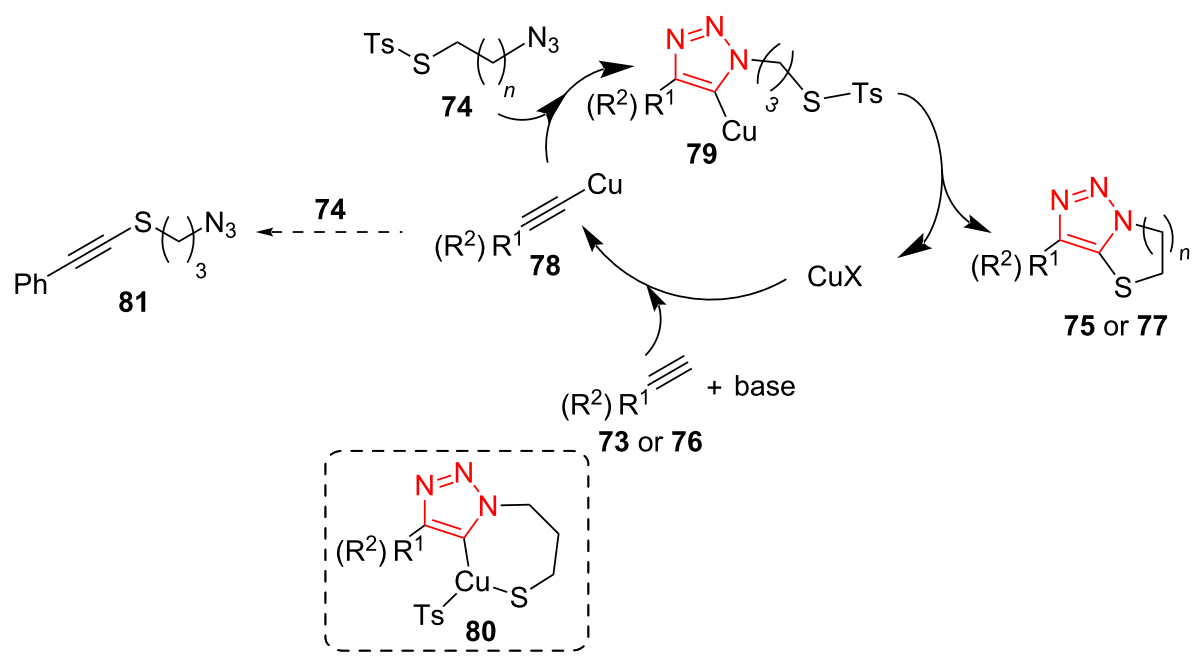

Scheme 24: A reasonable mechanism for the synthesis of sulfur-cycle-fused 1,2,3-triazoles 75 and 77. 


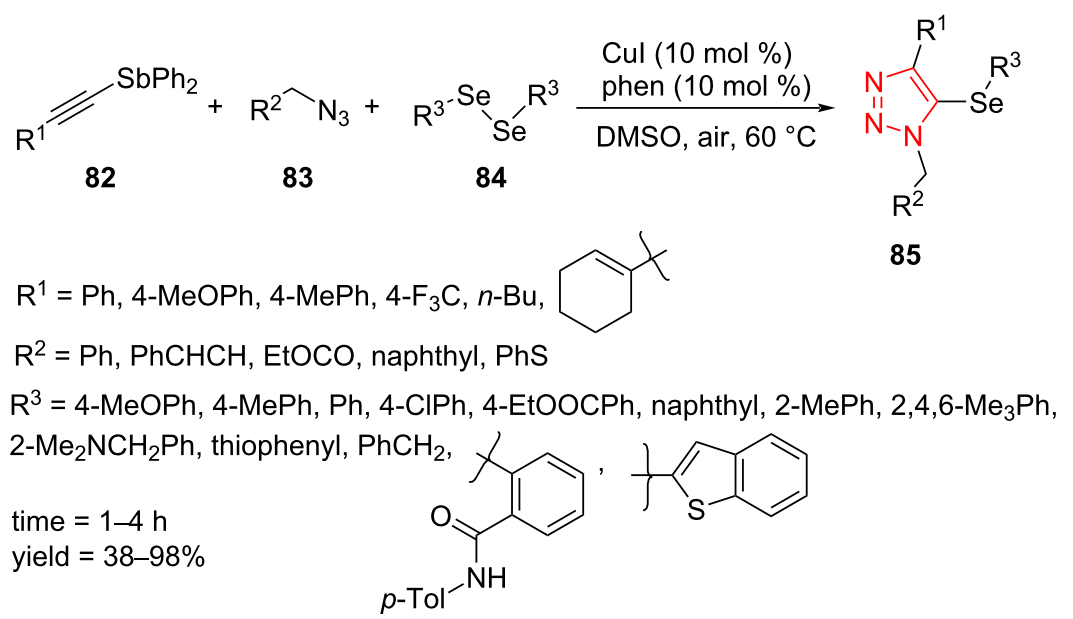

Scheme 25: Synthesis of 5-selanyltriazoles $\mathbf{8 5}$ from the reaction of ethynylstibanes $\mathbf{8 2}$, organic azides $\mathbf{8 3}$, and diaryl diselenides $\mathbf{8 4}$.

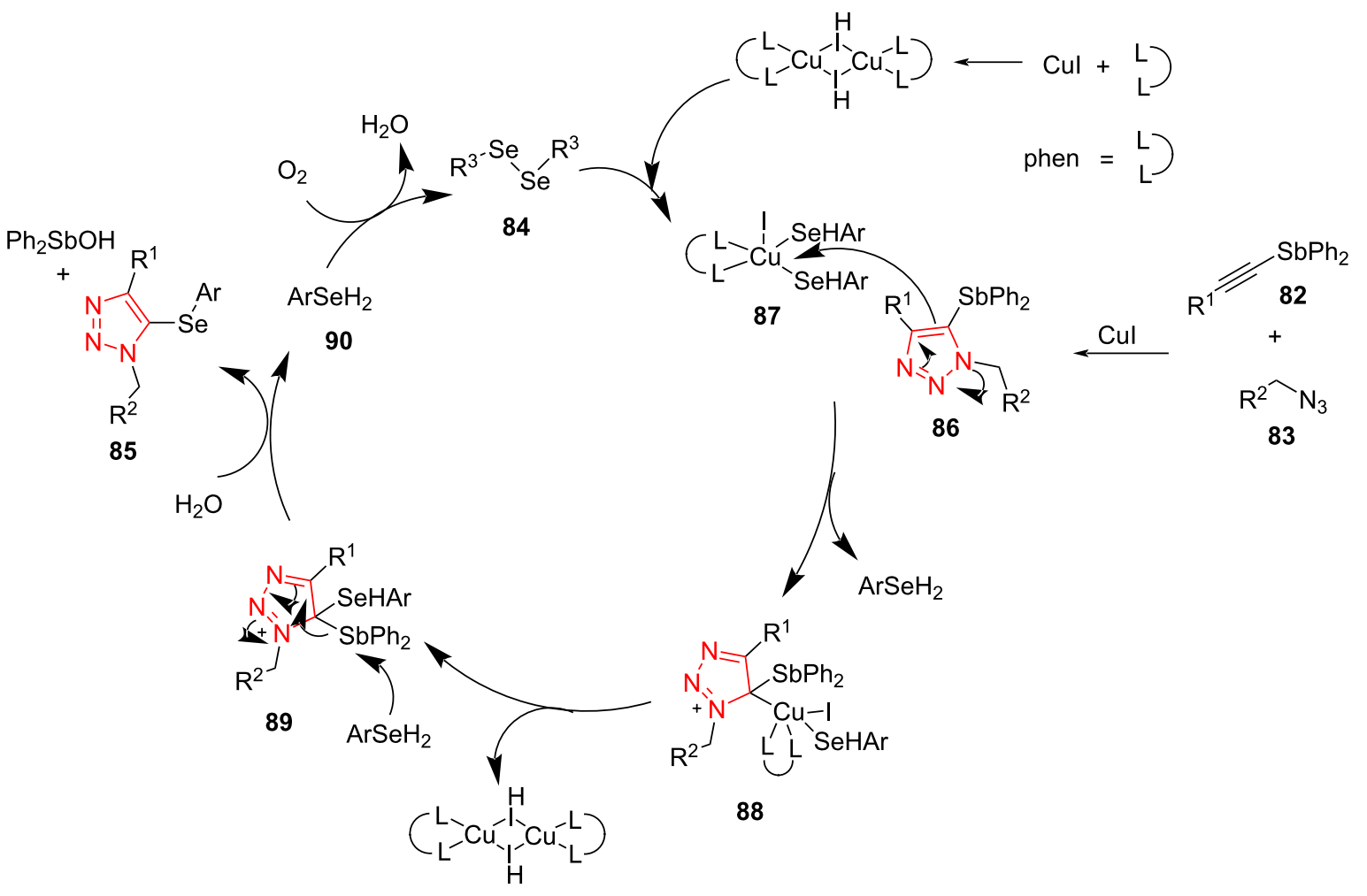

Scheme 26: A mechanism for the synthesis of 5-selanyltriazoles $\mathbf{8 5}$ from the reaction of ethynylstibanes $\mathbf{8 2}$, organic azides $\mathbf{8 3}$, and diaryl diselenides 84.

5-stibanotriazoles, this reinforces the importance of synthesizing 5-stibanotriazoles [54].

A similar reaction for the regioselective synthesis of triazole disulfides 98 through a copper(I)-catalyzed cycloaddition of azides 95, alkynes 96, and tert-butyl tosyl disulfide (97) was re- ported by $\mathrm{Xu}$ et al. The reaction has been achieved using a catalytic amount of $\mathrm{CuI}, \mathrm{LiO} t$-Bu, and $4 \AA$ molecular sieves in THF as solvent at $40{ }^{\circ} \mathrm{C}$ under $\mathrm{N}_{2}$ atmosphere for $12 \mathrm{~h}$ and proceeds via a multicomponent $\mathrm{CuAAC} /$ persulfuration sequence. The strategy features a wide substrate scope, and a wide variety of aliphatic moieties, (hetero)aromatic units with electron-donat- 


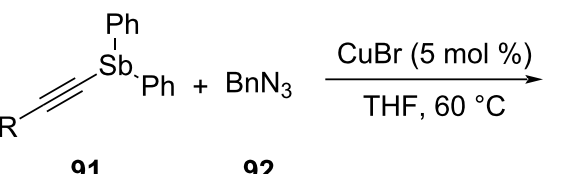

91

$\mathrm{R}=4-\mathrm{MeOPh}, 4-\mathrm{MePh}, \mathrm{Ph}$, 4-CF 3 Ph, 1-cyclohexenyl, $n$-Bu<smiles>[R]c1nnn(Cc2ccccc2)c1[SbH](c1ccccc1)c1ccccc1</smiles><smiles>[R]c1cn(Cc2ccccc2)nn1</smiles>

93

$70-77 \%$
94

$75-99 \%$

Scheme 27: Synthesis of trisubstituted triazoles containing an Sb substituent at position C5 in $\mathbf{9 3}$ and 5-unsubstituted triazoles $\mathbf{9 4 .}$

ing and electron-withdrawing groups, respectively, and ferrocenyl-substituted terminal alkynes was screened. Diverse triazoles disulfides 98 were achieved in good to high yield. Several aliphatic and aromatic azides were screened, producing a moderate to high yield of the desired products. Moreover, alkynes based on complex molecules, such as glucose, tyrosine, clofibrate, estrone, oleanane triterpenes, and vitamin E tolerated the reaction conditions and afforded the corresponding triazolo disulfides (Scheme 28) [55].

A probable mechanism for this transformation was proposed as illustrated in Scheme 29. The cycloaddition reaction between copper(I) acetylide 99 and organic azide 95 occurs to obtain the triazole cuprate intermediate $\mathbf{1 0 0}$, which reacts as a nucleophile with the disulfide electrophile $\mathbf{9 7}$ to produce the corresponding triazole disulfide 98 [55].

A convenient route to triazole-fused sultams $\mathbf{1 0 4}$ was reported by Latyshev et al. It comprises a modified $\mathrm{Cu}^{\mathrm{I}} \mathrm{AAC}$ cycloaddition to produce intermediate sulfonamide-tethered 5-iodo-1,2,3triazoles $\mathbf{1 0 3}$, followed by a base-mediated cyclization under catalyst-free conditions. A series of azidobenzenesulfonamides $\mathbf{1 0 1}$ was first synthesized from commercially available

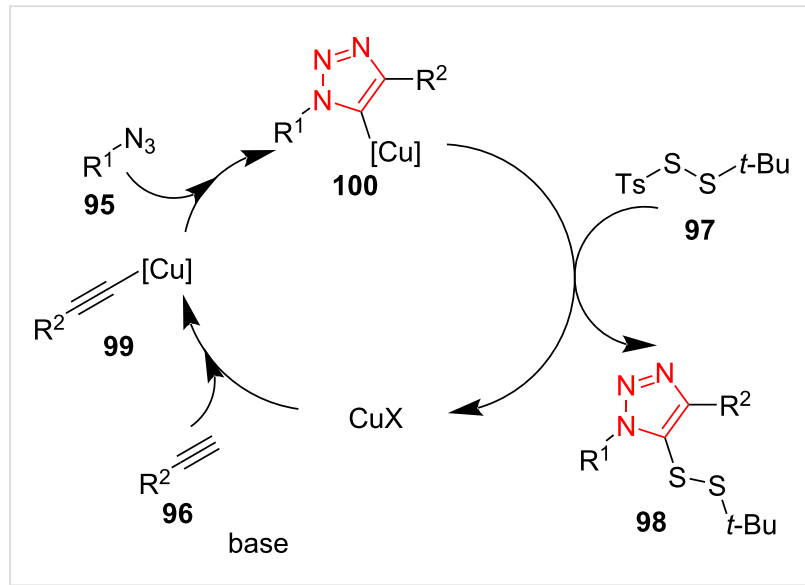

Scheme 29: A mechanism for the synthesis of asymmetric triazole disulfides 98 from disulfide-containing tert-butyl tosyl disulfide (97), alkynes 96 , and azides 95 .

orthanilic acid by a three-step procedure and then submitted to cycloaddition with different alkynes $\mathbf{1 0 2}$ using $\mathrm{CuI}$ and $\mathrm{Cu}$ as copper source, tris([1-(tert-butyl)-1H-1,2,3-triazol-4yl]methyl)amine (TTTA) as ligand, and THF as solvent at $50{ }^{\circ} \mathrm{C}$. The obtained sulfonamide-tethered 5-iodo-1,2,3-triazoles $\mathbf{1 0 3}$ were then cyclized upon heating in the presence of

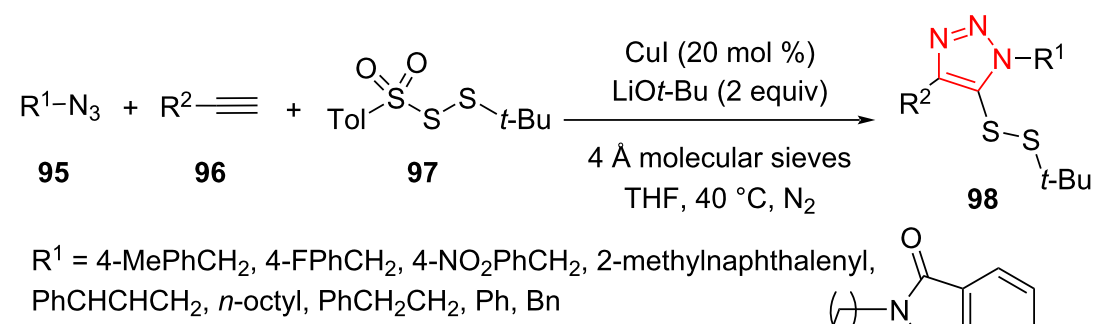

$\mathrm{R}^{2}=\mathrm{Ph}, 4-\mathrm{MePh}$, 4-MeOPh, 4-FPh, 4-BrPh, 4-CNPh, 4-F 3 CPh, 3-HOPh, thiophenyl, $\mathrm{PhOCH}_{2}, \mathrm{CH}_{3}\left(\mathrm{CH}_{2}\right)_{3}, \mathrm{HO}(\mathrm{CH})_{2}$, cyclopropyl,

time $=12 \mathrm{~h}$

yield $=43-89 \%$

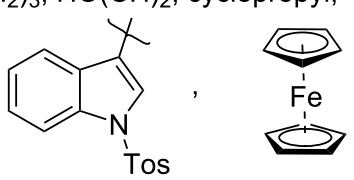


$\mathrm{Cs}_{2} \mathrm{CO}_{3}$ to give triazole-fused sultams 104. A good to excellent yield of sultam derivatives $\mathbf{1 0 4}$ containing aryl and alkyl substituents on the triazole ring was achieved under optimized conditions. The reaction displayed extensive diversity and excellent functional group tolerance It should be noted once again that $\mathrm{Cu}$-catalyzed triazoles were obtained in good to excellent yield by using $10 \% \mathrm{CuI}$ and $10 \% \mathrm{Cu}$, which were subsequently converted to fused sultams (Scheme 30) [56].

Anand et al. reported a $\mathrm{Cu}$-catalyzed one-pot method for the preparation of 1,2,3-triazole-fused tricyclic heterocycles 106 via an intramolecular [3+2]-annulation. This strategy includes the 1,6-conjugate addition of $\mathrm{Me}_{3} \mathrm{SiN}_{3}$ to $o$-alkynylated $p$-quinone methides 105, followed by an intramolecular Click annulation to provide rapid access to a wide range of desired 1,2,3-triazolefused isoindolines $\mathbf{1 0 8}$ with a reasonable yield. The reaction was carried out well by using $o$-alkynylated $p$-quinone methides 105 and $\mathrm{TMSN}_{3}$ in the presence of a catalytic amount of CuOTf.PhMe in DCE at $60{ }^{\circ} \mathrm{C}$. A series of $o$-alkynylated $p$-quinone methides containing electron-donating, electronwithdrawing, halogen, and alkyl groups was treated with $\mathrm{Me}_{3} \mathrm{SiN}_{3}$ under the optimized reaction conditions and produced the desired fused 1,2,3-triazole derivatives (Scheme 31) [57].
Two mechanisms for this transformation can be assumed. First, the $o$-alkynylated $p$-quinone methide $\mathbf{1 0 5}$ undergoes a 1,6conjugate addition with $\mathrm{Me}_{3} \mathrm{SiN}_{3}$ to give the intermediate 111, followed by the intramolecular Click annulation to afford the final product. A further possibility may be the creation of the 1,2,3-triazole intermediate 107, followed by intramolecular 1,6conjugate addition to afford the final product. To find the exact mechanism, the reaction was performed in $\mathrm{CDCl}_{3}$ as solvent in an NMR tube with a catalytic amount of $\mathrm{AgSbF}_{6}$ and then, the reaction mixture was analyzed using ${ }^{1} \mathrm{H}$ NMR spectroscopy. The ${ }^{1} \mathrm{H}$ NMR spectrum displayed two peaks at 6.28 and 5.19 ppm related to the benzylic and the phenolic $\mathrm{OH}$ protons, respectively, of the intermediate $\mathbf{1 0 6}$ (Scheme 32) [57].

Preparation of 5-aryl-substituted 1,2,3-triazole derivatives 112 through a $\mathrm{Cu}$-catalyzed reaction of alkynes $\mathbf{1 0 9}$, azides 110, and (hetero)arylboronic acid $\mathbf{1 1 1}$ was reported. The use of a catalytic amount of $\mathrm{CuCl}$ and $\mathrm{MeOLi}$ as base in $\mathrm{CH}_{3} \mathrm{CN}$ as solvent was recognized as the optimized conditions. This strategy provided a new procedure for the one-pot synthesis of fully decorated 1,2,3-triazole derivatives 112 in good to excellent yield at room temperature. First, several nonactivated arylalkynes containing electron-rich and electron-deficient groups as well as

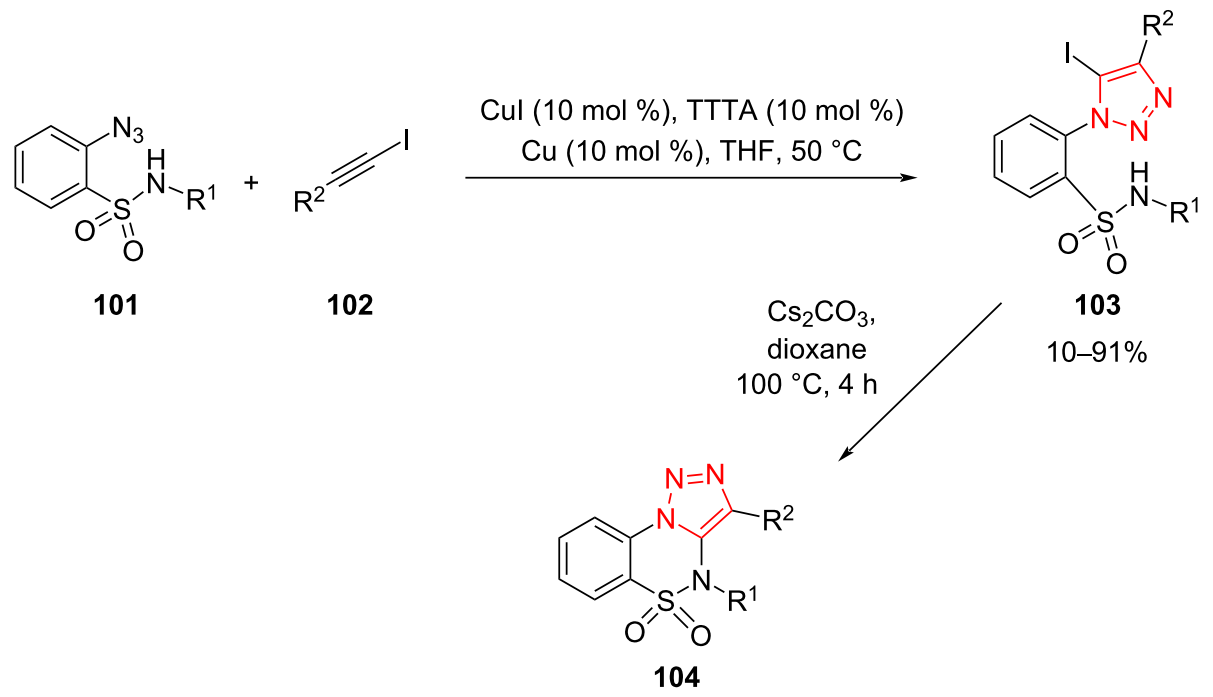

$\mathrm{R}^{1}=\mathrm{Me}, \mathrm{MeO}\left(\mathrm{CH}_{2}\right)_{2}$, $\mathrm{EtO}_{2} \mathrm{CCH}_{2}$, 4-MePh, $\mathrm{PhCH}_{2}, 2-\mathrm{H}_{2} \mathrm{NPhCH}_{2}$, cyclohexyl,<smiles>Cc1nocc1C(C)(C)C(C)(C)Cc1coc(C(C)(C)C)c1C(C)(C)C</smiles>

$\mathrm{R}^{2}=\mathrm{Bu}$, cyclopropyl, $\mathrm{HOCH}_{2}, \mathrm{HO}\left(\mathrm{CH}_{2}\right)_{2}, t-\mathrm{Bu}, 3,4-\mathrm{Me}_{2} \mathrm{OPh}, 3-\mathrm{MeO}_{2} \mathrm{CPh}, \mathrm{Ph}$,

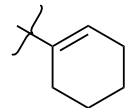


<smiles>[R]C#Cc1ccccc1C=C1C=C([R])C(=O)C([R])=C1</smiles>

105
$\mathrm{TMSN}_{3}$ (3 equiv) CuOTf.PhMe (10 mol \%)

DCE, $60^{\circ} \mathrm{C}$<smiles>[R1]c1cc2c(cc1[R])C(c1cc([R])c(O)c([R])c1)n1nnc([R3])c1-2</smiles>

106

$\mathrm{R}^{1}=t-\mathrm{Bu}, \mathrm{Me}$

$\mathrm{R}^{2}=\mathrm{H}, \mathrm{Me}, \mathrm{F}, \mathrm{MeO}, 2 \mathrm{MeO}$

$\mathrm{R}^{3}=4-\mathrm{PhPh}$, 4-MePh, 4- $t$-BuPh, 2,4,5-Me $\mathrm{Mh}_{3}$, $\mathrm{MeOPh}, 2-\mathrm{Me}-4-\mathrm{MeOPh}$, 4-OPhPh, 2-CIPh, 3-FPh, 2- $\mathrm{F}_{3} \mathrm{CPh}$, 4-CNPh, 3-FPh, 4- $\mathrm{MeO}_{2} \mathrm{CPh}$, $\mathrm{AcOCH}_{2}$, cyclohexyl- $\mathrm{CH}_{2}$, cyclohexyl, cyclopropyl,

time $=12-36 \mathrm{~h}$

yield $=40-82 \%$

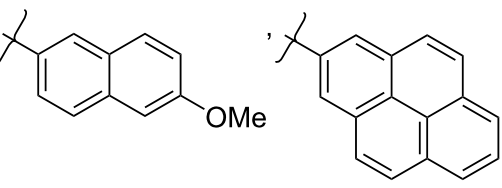<smiles>CC(C)(C)c1cc2ccccc2c2ccccc12</smiles>

Scheme 31: Synthesis of 1,2,3-triazole-fused tricyclic heterocycles 106.

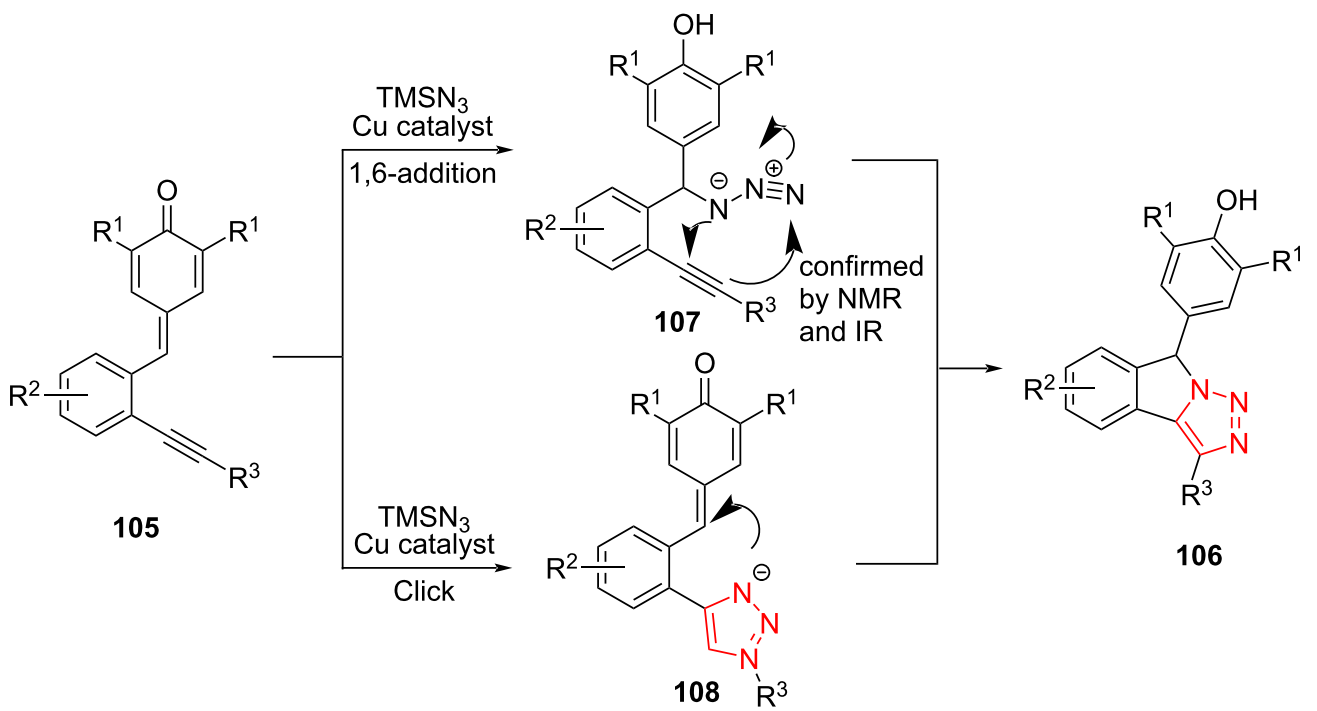

Scheme 32: A reasonable mechanism for the synthesis of 1,2,3-triazole-fused tricyclic heterocycles 106.

thiophene derivatives afforded the desired 5-arylated triazole derivatives. Then, the diversity of arylboronic acids was explored. The arylboronic acids containing some electron-rich, electron-deficient, and halogen moieties were good partners in these reactions as well, affording the 5-arylated triazoles with good to excellent yield (Scheme 33) [58].

A probable mechanism for this transformation is illustrated in Scheme 34. A copper acetylide intermediate $\mathbf{1 1 3}$ is first formed, which trough the $\mathrm{CuAAC}$ path generates the $\mathrm{C} 5$-cuprate tri- azole intermediate 115. The oxidative addition of arylboronic acid to the copper center forms the intermediate 116. The reductive elimination occurs to give the corresponding triazole $\mathbf{1 1 2}$ and to reform the copper catalyst for the next run [58].

\section{Postfunctionalization by $\mathrm{Pd}$ - or $\mathrm{Pd} / \mathrm{Cu}$ - catalyzed synthesis of fully decorated triazoles}

A palladium-catalyzed aminocarbonylation reaction of 5-iodo1,2,3-triazoles to give 1,4,5-trisubstituted 1,2,3-triazole-5- 


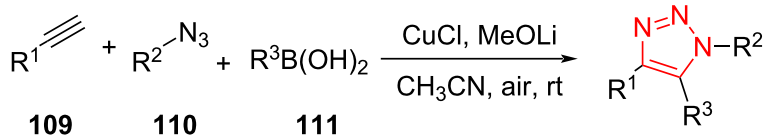

$$
\begin{aligned}
& 112
\end{aligned}
$$

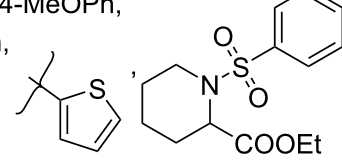

$\mathrm{R}^{2}=\mathrm{PhCH}_{2}, 4-\mathrm{MePhCH}_{2}, 4-\mathrm{BrPhCH}_{2}$, O 4- $\mathrm{PhPhCH}_{2}, \mathrm{PhCH}_{2} \mathrm{CH}_{2}$

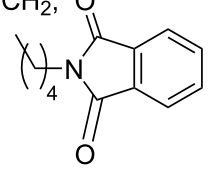

$\mathrm{R}^{3}=\mathrm{Ph}$, 4-MePh, 2-MePh, 4-iPrPh, 4-EtPh, 4-F $\mathrm{F}_{3} \mathrm{CP}$, 4-MeOOCPh, 4-FPh, 4-CIPh, 4-BrPh, 4-CNPh, 4-vinylbenzyl, thiophenyl

time $=12 \mathrm{~h}$

yield $=53-95 \%$

Scheme 33: Synthesis of 5-aryl-substituted 1,2,3-triazole derivatives 112.

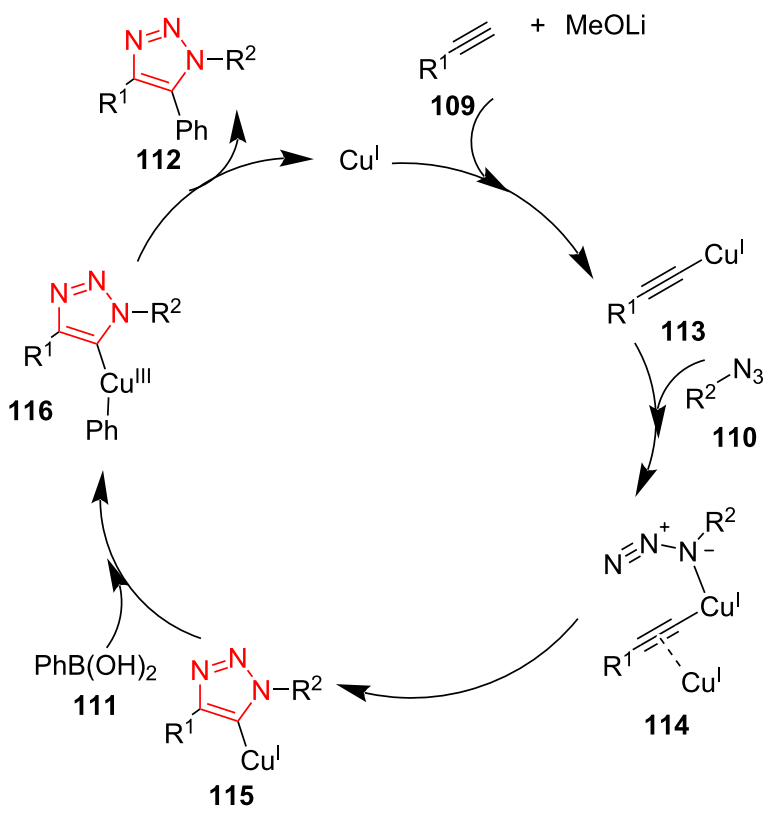

Scheme 34: A reasonable mechanism for the synthesis of 5-arylsubstituted 1,2,3-triazole derivatives 112

carboxamides 119 was introduced by Schwab et al. in 2019 . The 5-iodo-1,2,3-triazole 117, amine 118, and $\mathrm{CO}$ were reacted in the presence of a catalytic amount of $\mathrm{Pd}\left(\mathrm{PPh}_{3}\right)_{4}$ as well as $\mathrm{KOH}$ in $\left(\mathrm{CH}_{3} \mathrm{O}\right)_{2} \mathrm{CO}$ as solvent to obtain 1,2,3-triazole-5carboxamides 119. The reaction with several aliphatic primary amines led almost exclusively to the corresponding products.
However, no product was obtained using aliphatic secondary (aromatic) amines. In the next step, the effect of $\mathrm{R}^{1}$ and $\mathrm{R}^{2}$ groups on the triazole ring was also screened. These groups could be aliphatic or aromatic scaffolds. In almost all cases, the desired triazole compounds were formed in good to high yield. The short reaction time, high yield, the use of dimethyl carbonate as a sustainable solvent, the use of an efficient alternative source of carbon monoxide, and avoiding a pressurized cylinder are some benefits of this protocol (Scheme 35) [59].

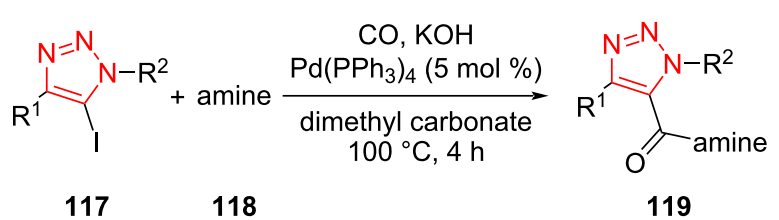

Scheme 35: Synthesis of 1,4,5-trisubstituted 1,2,3-triazole-5-carboxamides 119.

A feasible mechanism is illustrated for the synthesis of 1,2,3-triazole-5-carboxamides. The reaction includes oxidative addition of 5-iodo-1,2,3-triazole $\mathbf{1 1 7}$ to a Pd center to achieve the intermediate 120. The intermediate $\mathbf{1 2 1}$ is formed via coordination and insertion of CO to intermediate 120. Then, the intermediate 122 is obtained via a nucleophilic attack of amine 118. Finally, a reductive elimination occurs in the presence of base to achieve the desired product 119 (Scheme 36) [59].

Direct arylation of disubstituted triazoles $\mathbf{1 2 3}$ with aryl halides 124 using a $\mathrm{Pd} / \mathrm{C}$ catalyst under solvent-free conditions to give fully decorated triazoles $\mathbf{1 2 5}$ was reported by Farinola et al. Different aryl iodides containing electron-donating and electronwithdrawing groups exhibited good to excellent results in the reaction. Notably, the yield of the Click reaction with 2-iodotoluene decreased due to the steric effects. Moreover, the utilization of an efficient heterogeneous catalyst and insensitivity to air are advantages of this reaction (Scheme 37) [60].

In 2017, De Borggraeve et al. explained a convenient procedure for the preparation of triazolo[1,5- $a$ ] indolones 131 through an intramolecular cyclization via an unprecedented Pd-catalyzed carbonylative $\mathrm{C}-\mathrm{H}$ functionalization of 1-(2-bromoaryl)1,2,3-triazoles 130. The triazole derivatives were prepared starting from 2-bromoaniline derivatives $\mathbf{1 2 6}$ that were transformed into desired 1-azido-2-bromobenzenes 127 using $t$-BuONO and $\mathrm{TMSN}_{3}$. Next, 2-bromophenyl azide derivatives 127 were reacted with phenylacetaldehyde (128) or alkynes 129 to afford sterically hindered 1-(2-bromophenyl)-1,2,3-triazole derivatives 130. The target compounds, triazolo[1,5- $a$ ] indolones 131, were then obtained from $\mathbf{1 3 0}$ in high yield using catalytic amounts of $\mathrm{Pd}(\mathrm{OAc})_{2}$ and $\mathrm{PCy}_{3}$, carbon monoxide, and potas- 


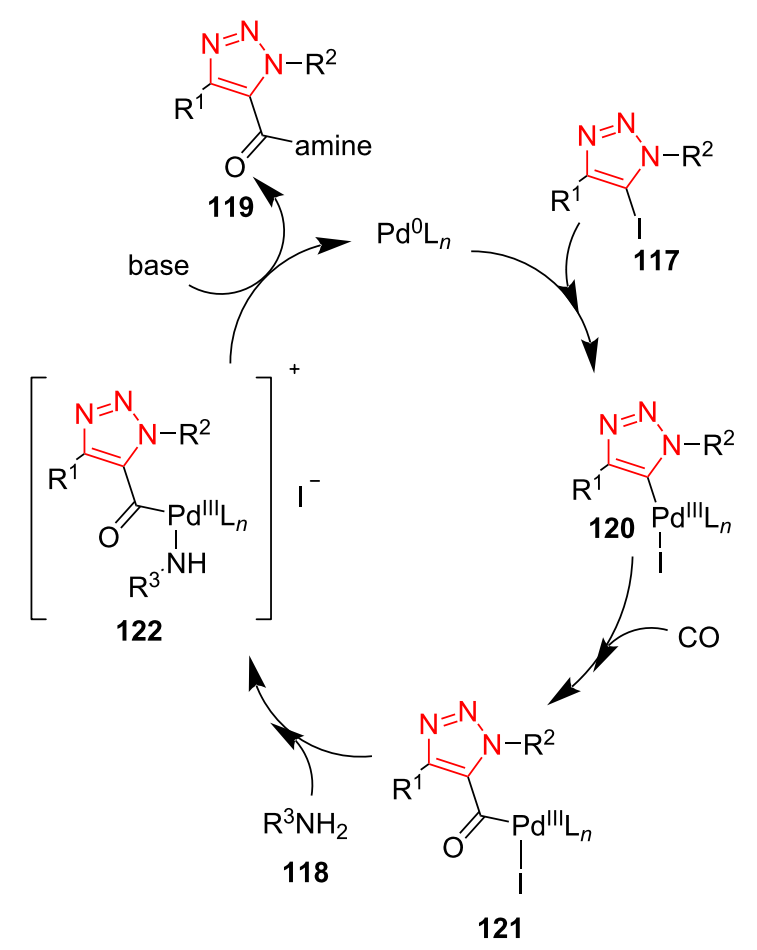

Scheme 36: A probable mechanism for the synthesis of 1,4,5-trisubstituted 1,2,3-triazole-5-carboxamides 119.

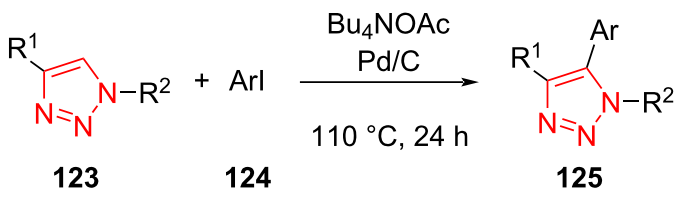

$\mathrm{R}^{1}=\mathrm{Ph}, \mathrm{C}_{5} \mathrm{H}_{11}, p-\mathrm{CH}_{3} \mathrm{Ph}, \mathrm{C}_{6} \mathrm{H}_{13}$

$\mathrm{R}^{2}=\mathrm{C}_{16} \mathrm{H}_{33}, \mathrm{CH}_{2} \mathrm{CH}_{2} \mathrm{Ph}, \mathrm{C}_{8} \mathrm{H}_{17}, p-\mathrm{CH}_{3} \mathrm{Ph}$

$\mathrm{Ar}=\mathrm{Ph}, 3-\mathrm{MePh}, 4,5-\mathrm{Me}_{2} \mathrm{Ph}, 4-\mathrm{FMe}, 4-\mathrm{NO}_{2} \mathrm{Ph}, 2-$

$\mathrm{MePh}, 3-\mathrm{MeOPh}, 4-\mathrm{CF}_{3} \mathrm{Ph}, 3,5-\mathrm{Me}_{2} \mathrm{Ph}$, pyridyl

time $=24 \mathrm{~h}$

yield $=44-81 \%$

Scheme 37: Synthesis of fully decorated triazoles 125 via the $\mathrm{Pd} / \mathrm{C}$ catalyzed arylation of disubstituted triazoles $\mathbf{1 2 3}$ with aryl halides 124.

sium carbonate and with heating in toluene at $120{ }^{\circ} \mathrm{C}$. The structure of one of the products was proved by NMR analysis and X-ray crystallography. A number of different substituents was introduced to the bromotriazole scaffold, where unsubstituted and electron-rich derivatives gave a good yield, while the presence of electron-withdrawing groups decreased the product yield (Scheme 38) [61].

A number of 4-ethynyl-5-iodo-1,2,3-triazoles 134 have been synthesized through the $\mathrm{Cu}$-catalyzed 1,3-dipolar cycloaddition<smiles>[R]c1cn(-c2ccccc2Br)nn1</smiles>

130

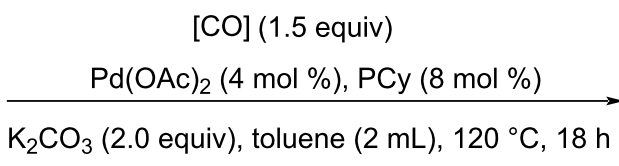

[CO] ( 1.5 equiv)

$\mathrm{CO}_{3}\left(2.0\right.$ equiv), toluene $(2 \mathrm{~mL}), 120^{\circ} \mathrm{C}, 18 \mathrm{~h}$<smiles>[R]c1nnn2c1C(=O)c1ccccc1-2</smiles>

131

$0-93 \%$

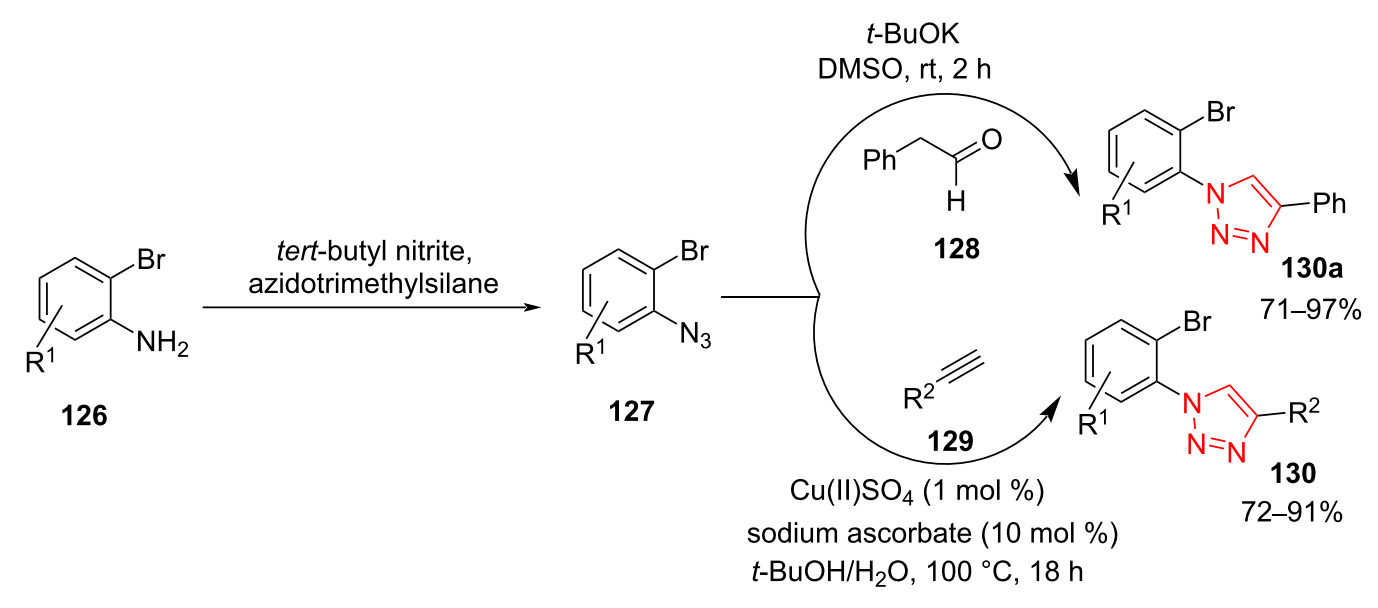

$\mathrm{R}^{1}=\mathrm{H}, 4-\mathrm{Me}, 4-\mathrm{MeO}, 4-\mathrm{F}, 2-\mathrm{Br}-5-\mathrm{F}, 2-\mathrm{Br}-4,6-\mathrm{Me}_{2}$, 2-Br-3-Me, 2-Br-4-CO $\mathrm{CO}_{2}$

$\mathrm{R}^{2}=4-\mathrm{MePh}$, 4-t-BuPh, 4-MeOPh, 4-FPh, 4-F $\mathrm{F}_{3} \mathrm{CPh}$, cyclopropyl, $n$-hexyl, $\mathrm{SiMe}_{3}, \mathrm{SiiPr}_{3}$, thiophenyl 
of iododiacetylenes 132 with organic azides 133 using $\mathrm{CuI}\left(\mathrm{PPh}_{3}\right)_{3}$ and 2,6-lutidine as a catalytic system at room temperature. Then, 4-ethynyl-5-iodo-1,2,3-triazoles 134 were used as starting material in the Sonogashira and Suzuki reactions. The Sonogashira-Hagihara cross-coupling led to alkynylation at position 5 of the triazole ring in the presence of $\mathrm{CuI}$ and $\mathrm{Pd}\left(\mathrm{PPh}_{3}\right)_{4}$ as catalytic system as well as $\mathrm{K}_{3} \mathrm{PO}_{4}$ as base in THF as solvent at $65{ }^{\circ} \mathrm{C}$. However, the Suzuki-Miyaura cross-coupling produced a series of 5-aryl-4-ethynyl triazoles 136 in the presence of $\mathrm{Pd}\left(\mathrm{PPh}_{3}\right)_{4}$ as catalyst and $\mathrm{K}_{3} \mathrm{PO}_{4}$ as base in 1,4dioxane as solvent at $100{ }^{\circ} \mathrm{C}$ (Scheme 39) [62].

A paper by Sekar et al. described the synthesis of polycyclic triazoles 142 through a domino alkyne insertion and $\mathrm{C}-\mathrm{H}$ bond functionalization reaction sequence with triazole-bearing aryl iodide 140, catalyzed by alloy-structured $\mathrm{Pd} / \mathrm{Cu}$ bimetallic nanoparticles stabilized by a binaphthyl moiety, $\mathrm{Pd} / \mathrm{Cu}-\mathrm{BNP}$ 139. The $\mathrm{Pd} / \mathrm{Cu}-\mathrm{BNP}$ nanoparticles 139 were demonstrated to be an efficient and recyclable catalyst, and triazoles carrying alkyl substituents as well as electron-rich and electron-poor aryl groups afforded the corresponding products $\mathbf{1 4 2}$ in good to excellent yield. A moderate to good yield was achieved when numerous diarylacetylenes 141 substituted by 4-Me, 4-OMe, F, $\mathrm{CF}_{3}, \mathrm{CO}_{2} \mathrm{Et}$, and $\mathrm{CN}$ were employed in this transformation (Scheme 40). The synthetic route for the $\mathrm{Pd} / \mathrm{Cu}-\mathrm{BNP}$ nanoparticles 139 is also shown in Scheme 40. Pd/Cu-BNP was synthesized by the following procedure as illustrated in Scheme 40.

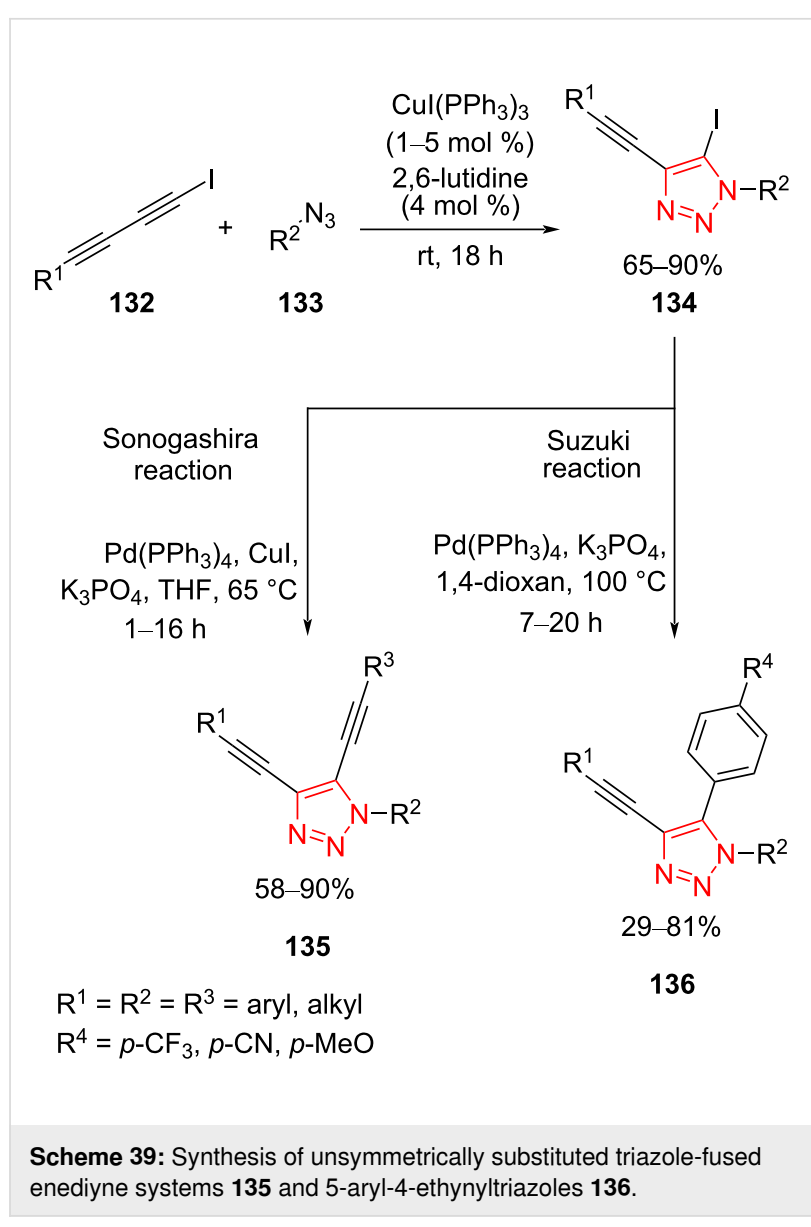<smiles>Nc1ccc2ccccc2c1-c1c(N)ccc2ccccc12</smiles>

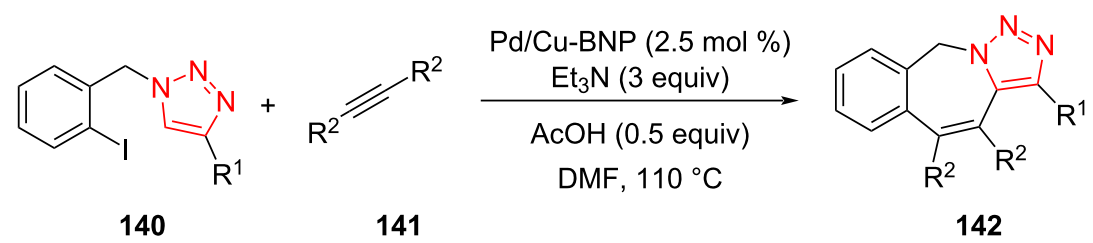

$\mathrm{R}^{1}=\mathrm{Ph}, 4-\mathrm{MePh}, n$-pentylphenyl, 4-MeOPh, 3-MePh, $n$-Bu, $t$-Bu, Cy $\mathrm{R}^{2}=\mathrm{Ph}, 4-\mathrm{MePh}, 4-\mathrm{MeOPh}, 3-\mathrm{FPh}, 4-\mathrm{CIPh}, 4-\mathrm{CF}_{3} \mathrm{Ph}, 4-\mathrm{CO}_{2} \mathrm{EtPh}, 4-\mathrm{CNPh}$, thiophenyl, 4-FPh, 4-CIPh, 4- $\mathrm{CF}_{3} \mathrm{Ph}, 4-\mathrm{CO}_{2} \mathrm{EtPh}$

time $=20-36 \mathrm{~h}$

yield $=68-93 \%$ 
First, 1,1'-binaphthyl-2,2'-diamine (BINAM, 137) was transformed to [1,1'-binaphthalene]-2,2'-bis(diazonium) tetrafluoroborate (138) in the presence of $\mathrm{HBF}_{4}$ and $\mathrm{NaNO}_{2}$ at $0{ }^{\circ} \mathrm{C}$. Next, the nanoparticles were obtained from the reduction of $\mathrm{Pd}(\mathrm{OAc})_{2}$ and $\mathrm{Cu}(\mathrm{OAc})_{2}$ employing $\mathrm{NaBH}_{4}$ in the presence of diazonium salt [63].

A possible mechanism for the synthesis of polycyclic triazoles 142 was proposed by Sekar et al. as well [63]. First, the nanocatalyst $\mathbf{1 3 9}$ is inserted in the $\mathrm{C}-\mathrm{I}$ bond to obtain the intermediate 143. Then, the insertion of diarylacetylenes 141 forms intermediate 144. In continuation, the acetate anion formed by reaction of $\mathrm{AcOH}$ with $\mathrm{Et}_{3} \mathrm{~N}$ undergoes a ligand exchange with iodide to produce the intermediate 145. Later, carboxylateligand-assisted $\mathrm{C}-\mathrm{H}$ bond activation takes place through a concerted metalation-deprotonation transformation to produce the next intermediate. Finally, the corresponding product $\mathbf{1 4 2}$ is formed by a reductive elimination process, along with the regeneration of the active catalytic species for the subsequent catalytic run (Scheme 41) [63].

Kumar et al. presented a novel protocol for the synthesis of highly functionalized 1,2,3-triazole-fused 5-, 6-, and 7-mem- bered rings 152-154 via azide-alkyne cycloaddition, followed by $\mathrm{C}\left(\mathrm{sp}^{2}\right)-\mathrm{H}$ functionalization of the 1,2,3-triazole intermediate through an isocyanide insertion. The significant benefits of this strategy were simple substrates, few synthetic steps, and high diversity. A range of $o$-azidophenols $\mathbf{1 4 8}$ as well as the compounds 150 and 151, along with alkynes 149 and isocyanides, were employed to survey the diversity of highly functionalized tricyclic triazoles 152-154. It was proved that $o$-azidophenols 148 react well with alkynes 149 using $\mathrm{CuI}$ in $\mathrm{DMF}$ at $120^{\circ} \mathrm{C}$ and then, the resulting intermediates react with isocyanides using $\mathrm{Pd}(\mathrm{OAc})_{2}$ and an $\mathrm{O}_{2}$ atmosphere at $120{ }^{\circ} \mathrm{C}$ to produce the desired products (Scheme 42). $o$-Azidophenols 148 were treated with aryl and aliphatic alkyne partners and then with tert-butyl and cyclohexyl isocyanide to give 1,2,3-triazolefused oxazines 152. The reaction was extended to 2-(azidophenyl)methanol species $\mathbf{1 5 0}$, which were treated with ethynylbenzene and cyclohexyl isocyanide, and in all cases, the corresponding oxazepines $\mathbf{1 5 3}$ were obtained in good yield [63].

The 1-azido-2-bromobenzenes $\mathbf{1 5 1}$ with $\mathrm{H}, \mathrm{Me}, \mathrm{F}, \mathrm{Cl}$, and $\mathrm{CF}_{3}$ substituents, respectively, on the phenyl ring were then tested in the reaction with phenylacetylene (149a), followed by treatment with tert-butyl isocyanide or cyclohexyl isocyanide under

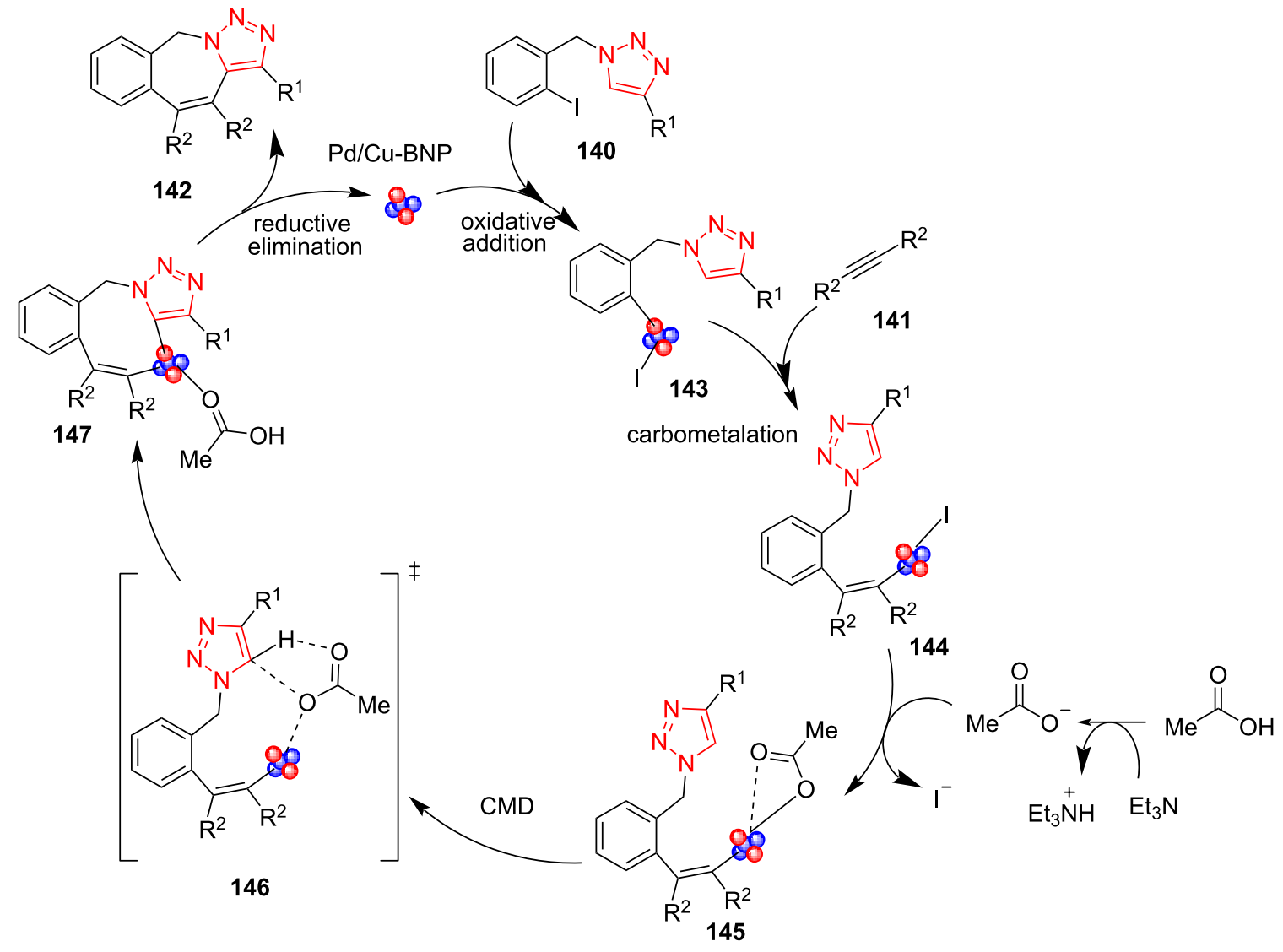




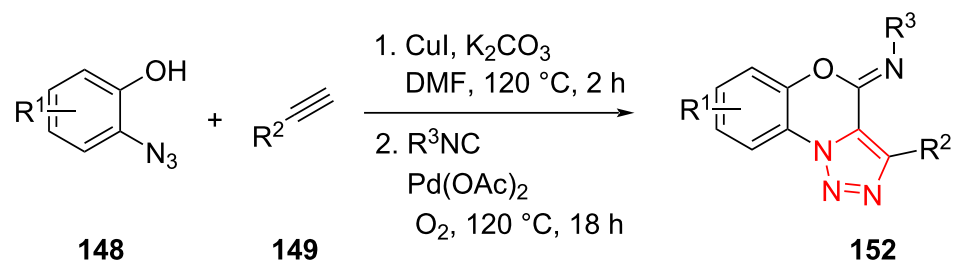

$\mathrm{R}^{1}=\mathrm{H}, t-\mathrm{Bu}, \mathrm{Cl}$,

yield $=65-72 \%$

$\mathrm{R}^{2}=\mathrm{Ph}, 4-\mathrm{MePh}$, 4-MeOPh, $\mathrm{CH}_{3}\left(\mathrm{CH}_{2}\right)_{3}, \mathrm{CH}_{3}\left(\mathrm{CH}_{2}\right)_{4}$

$\mathrm{R}^{3}=t-\mathrm{Bu}, \mathrm{Cy}$<smiles>[R]#C[O+]</smiles>

150

$\mathrm{R}^{1}=\mathrm{Cl}, \mathrm{H}$

$\mathrm{R}^{2}=\mathrm{Ph}$

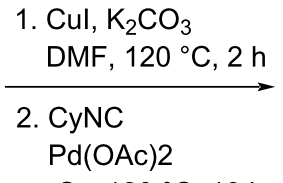

$\mathrm{O}_{2}, 120^{\circ} \mathrm{C}, 18 \mathrm{~h}$<smiles>[R]c1nnn2c1/C(=C/[Al])OCc1c[R1]ccc1-2</smiles>

153<smiles>[N]c1c[R1]ccc1Br</smiles>

151<smiles>[R]C#CC</smiles>

1. Cul, $\mathrm{K}_{2} \mathrm{CO}_{3}$ DMF, $120^{\circ} \mathrm{C}, 2 \mathrm{~h}$

2. $\mathrm{R}^{3} \mathrm{NC}, \mathrm{Pd}(\mathrm{OAC})_{2}$ $\mathrm{PCy}_{3}, \mathrm{~N}_{2}, 120^{\circ} \mathrm{C}, 18 \mathrm{~h}$

$\mathrm{R}^{1}=\mathrm{H}, \mathrm{Me}, 2 \cdot \mathrm{Me}, \mathrm{Cl}, \mathrm{F}, \mathrm{CF}_{3}$

$\mathrm{R}^{2}=\mathrm{Ph}$<smiles>[N]c1cc[R1]cc1O</smiles>

148

(1 equiv)

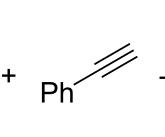

149a

( 0.5 equiv)

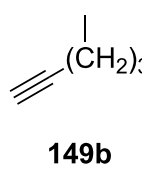

( 0.5 equiv)
1. Cul, $\mathrm{K}_{2} \mathrm{CO}_{3}$ DMF, $120^{\circ} \mathrm{C}, 2 \mathrm{~h}$

2. $t$-BuNC (1 equiv) $\mathrm{Pd}(\mathrm{OAc})_{2}$ $\mathrm{O}_{2}, 120^{\circ} \mathrm{C}, 18 \mathrm{~h}$<smiles>[R]C=NC1c2cc[R1]cc2-n2nnc([R])c21</smiles>

154 yield $=68-75 \%$

Scheme 42: Synthesis of highly functionalized 1,2,3-triazole-fused 5-, 6-, and 7-membered rings 152-154

nearly the same conditions to give diverse 1,2,3-triazole-fused indolylidenes 154. In this case, it was necessary to use $\mathrm{PCy}_{3}$ as a ligand for $\mathrm{Pd}$ and $\mathrm{N}_{2}$ atmosphere.

Finally, the reactivity of aromatic and aliphatic alkynes was compared performing the reaction of $o$-azidophenol $148 \mathrm{a}$ ( 1 equiv), phenylacetylene (149a, 0.5 equiv) and aliphatic alkyne 149b ( 0.5 equiv) with tert-butyl isocyanide (1.0 equiv) under standard reaction conditions (Scheme 42). It was found that the arylalkyne is much more reactive than the aliphatic alkyne under standard reaction conditions, giving the corresponding condensed triazole 152a [64].

A probable mechanism for this transformation is illustrated in Scheme 43. An azide substrate 148, 150, or $\mathbf{1 5 1}$ is treated with a nonactivated alkyne 149 using $\mathrm{CuI}$ as catalyst and $\mathrm{K}_{2} \mathrm{CO}_{3}$ as base to obtain the 1,4-disubstitued 1,2,3-triazole intermediate 155-157, respectively. The 1,2,3-triazole-based phenol or alcohol coordinates to the Pd center to form complex 158. Then, the electrophilic palladation of the 1,2,3-triazole ring occurs to achieve $\mathrm{Pd}(\mathrm{II})$ intermediate 159. Isocyanide migrates to $\mathbf{1 5 9}$ to obtain the seven- or eight-membered palladium cycle 160. The reductive elimination of $\mathbf{1 6 0}$ takes place, which is followed by tautomerization to produce the desired product 152 or 153 and the $\operatorname{Pd}(0)$ species, which is then oxidize to $\mathrm{Pd}(\mathrm{II})$ in the presence of $\mathrm{O}_{2} \cdot \operatorname{Pd}(0)$ species were inserted into bromo-substituted 1,2,3-triazole $\mathbf{1 5 5}-\mathbf{1 5 7}$, respectively, to afford further intermediate $\mathbf{1 5 8}^{\prime}$. The isocyanide is inserted into intermediate 158' to achieve intermediate 159'. A 1,2,3-triazole $\mathrm{C}-\mathrm{H}$ bond activation occurs using palladium, which subsequently undergoes a reductive elimination process to afford final product $\mathbf{1 5 4}$. Likewise, the $\operatorname{Pd}(0)$ species is reformed for the next cycle [64]. 


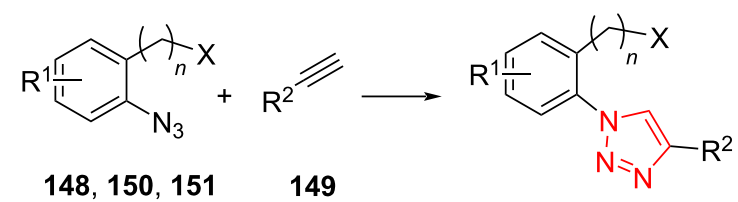

$155-157$

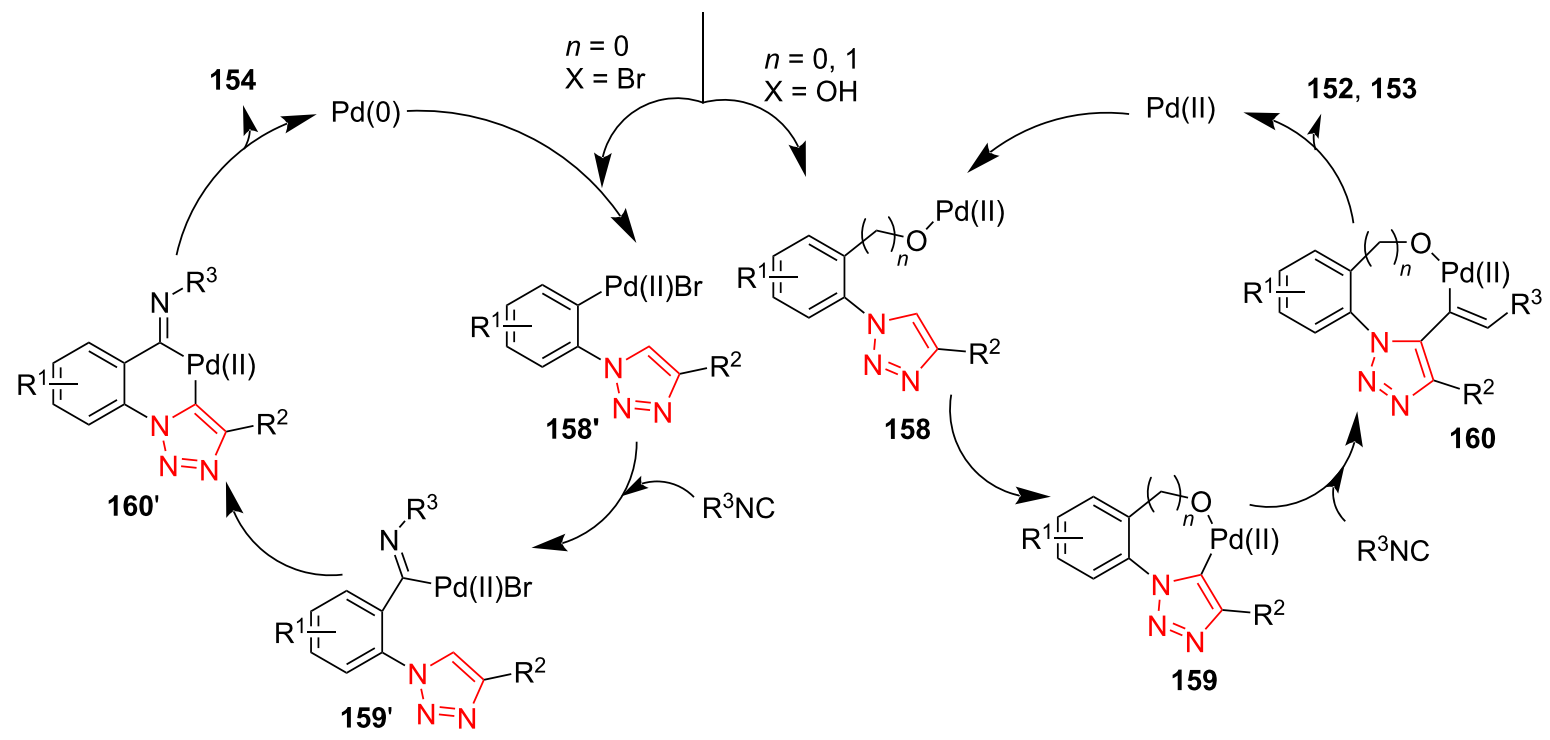

Scheme 43: A probable mechanism for the synthesis of highly functionalized 1,2,3-triazole-fused 5-, 6-, and 7-membered rings 152-154, respectively.

The synthesis of fully decorated 1,2,3-triazoles $\mathbf{1 6 2}, \mathbf{1 6 4}$, and 166 was reported by Ackermann et al. via intramolecular oxidative $\mathrm{C}-\mathrm{H}$ arylation of 1,2,3-triazoles 161, 163, and 165 using a reusable palladium catalyst in PEG, Pd@PEG, under $\mathrm{O}_{2}$ atmosphere. The main advantages of this strategy include i) a versatile methodology for aerobic $\mathrm{C}-\mathrm{H}$ activation; ii) PEG as green and recyclable reaction medium; and iii) a reusable palladium catalyst complex [65].

Fully functionalized 1,2,3-triazolo-fused chromenes 162, 164, and 166 were regioselectively prepared in moderate yield. The isoindoline-fused triazoles 164 were achieved using dehydrogenative intramolecular cyclization of 4-substituted $\mathrm{N}$-benzyltriazoles 163. A phenyl, alkyl, and $\mathrm{CO}_{2} \mathrm{Me}$ group, respectively, on the triazole scaffold was tolerated under the reaction conditions to form 4 -substituted $N$-benzyltriazoles (Scheme 44 ). The substituted phenanthro[9,10- $d$ ] triazoles 166 were also prepared through the cyclodehydrogenative arylation of $\mathbf{1 6 5}$. It was demonstrated that the Pd and PEG mixture could be reused for further cycles, and only a catalytic amount of the copper source, pivalic acid, and the substrates needed to be added [65]. As shown in Scheme 44, this methodology was extended to the synthesis of potentially bioactive derivatives, such as heterofused coumarins 162a and $162 \mathrm{~b}$, azepinone-like 162c, and steroid-based triazolo-fused isoindoline 162d [65].

\section{Ru-catalyzed synthesis of fully decorated tri- azoles}

A series of 1,4,5-trisubstituted triazoles $\mathbf{1 7 2}$ was prepared by Ru-catalyzed [3 + 2]-cycloaddition of ynoate esters 170 with azide to produce metal-bound heterocyclic complexes 171 via an intramolecular cycloaddition reaction. The ynoate esters including diethyl acetylenedicarboxylate, ethyl 4,4,4-trifluoro-2butynoate, methyl phenylpropiolate, and ethyl 2-butynoate successfully generated the metal-bound heterocyclic complexes. The alkylation reaction of 171a led to the bond cleavage between ruthenium and nitrogen to produce several 1-alkylated 4,5-bis(ethoxycarbonyl)-1,2,3-triazoles 172 [66]. Herein, the sodium azide initially reacts with $[\mathrm{Ru}]-\mathrm{Cl} \mathbf{1 6 8}$ to produce $[\mathrm{Ru}]-\mathrm{N}_{3}$ 169. Then, the resulting intermediate cyclizes with ynoate ester 170 to form metal-bound heterocyclic complex 171. This metal-bound heterocyclic complex 171 reacts with alkyl halide to produce final product $\mathbf{1 7 2}$ via a bond cleavage between ruthenium and nitrogen (Scheme 45) [66].

\section{$\mathrm{Cu} / \mathrm{Ru}$-catalyzed synthesis of fully decorated triazoles}

A novel strategy to transform nonactivated aromatic and aliphatic alkynes 173 to 4-cyano-1,2,3-triazoles 175 was developed by Zhu et al. This reaction involved a two-step sequence. Initially, 1-cyanoalkynes $\mathbf{1 7 4}$ were generated and 

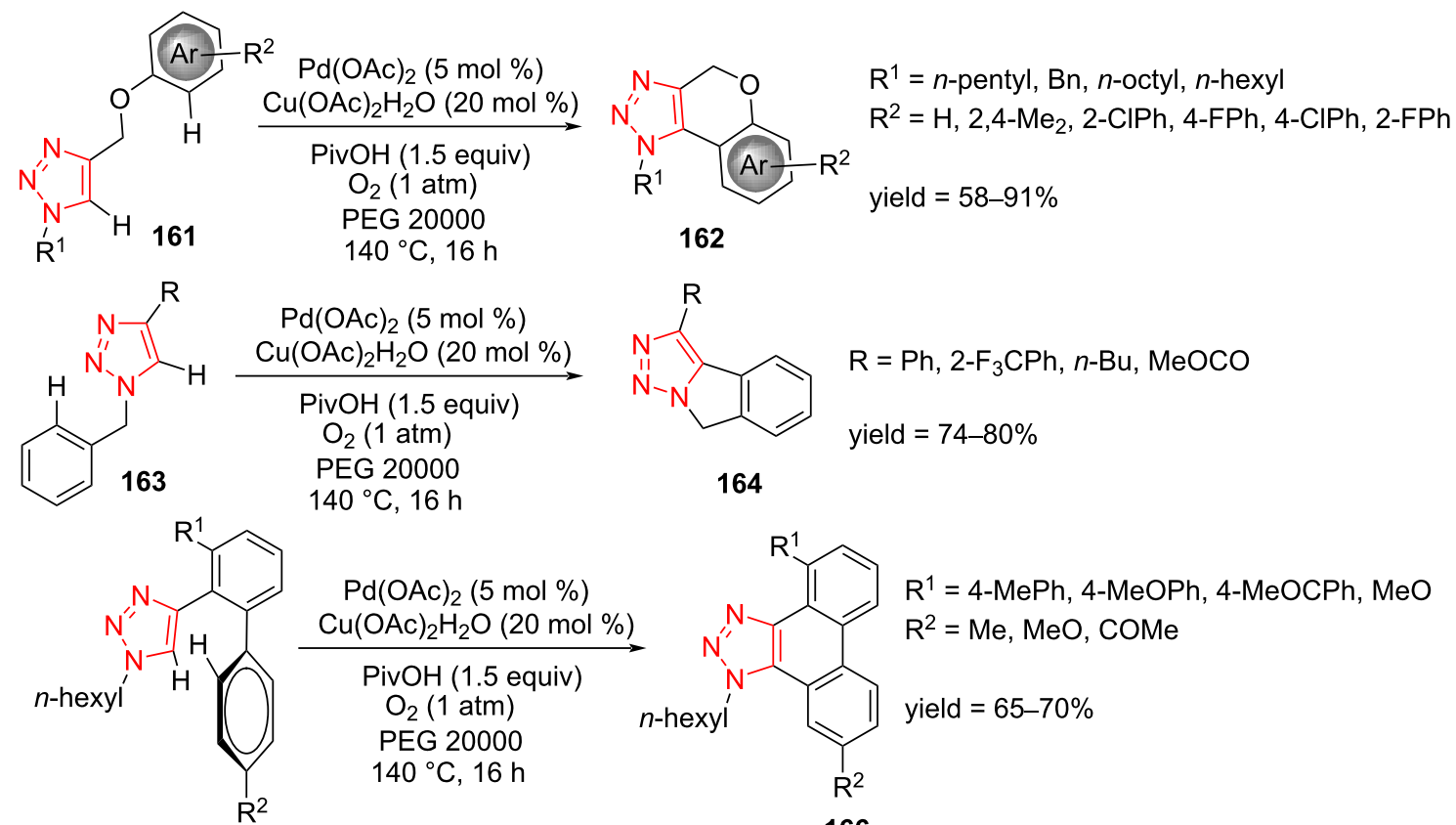

165
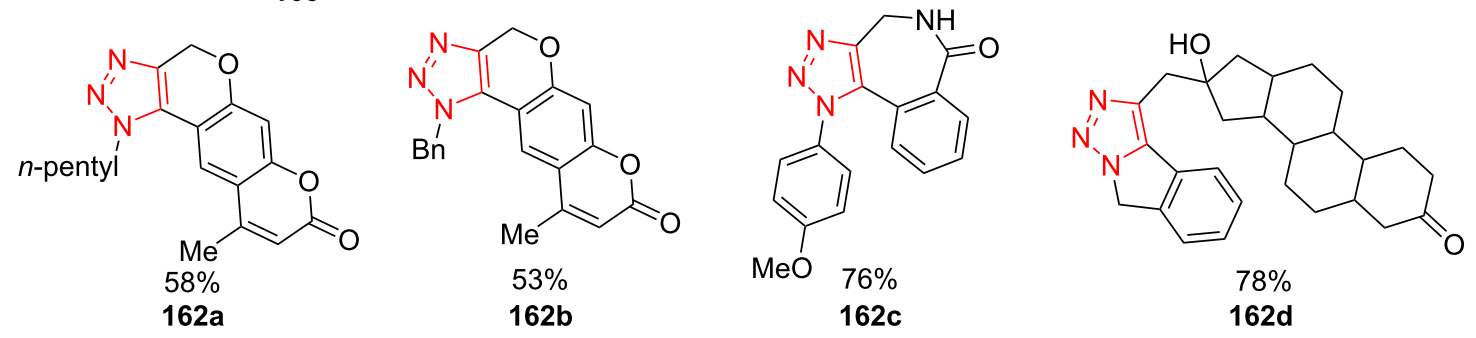

Scheme 44: Synthesis of fully functionalized 1,2,3-triazolo-fused chromenes 162,164 , and 166 via the intramolecular oxidative C-H arylation of 1,2,3-triazoles 161,163 , and 165 .

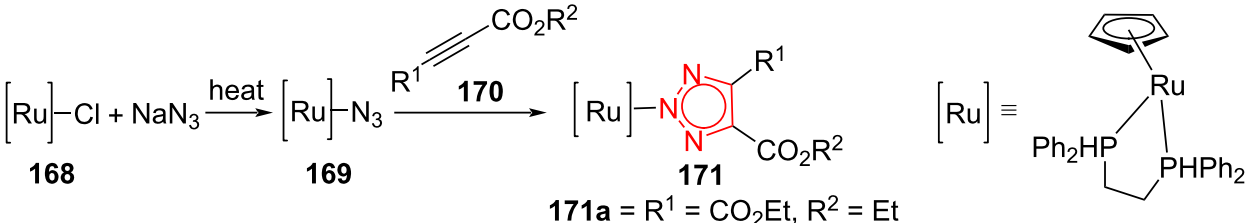

$$
\begin{aligned}
& 171 b=R^{1}=\mathrm{CF}_{3}, \mathrm{R}^{2}=\mathrm{Et} \\
& 171 \mathrm{c}=\mathrm{R}^{1}=\mathrm{Ph}, \mathrm{R}^{2}=\mathrm{Me} \\
& 171 d=R^{1}=C_{3}, R^{2}=E t
\end{aligned}
$$

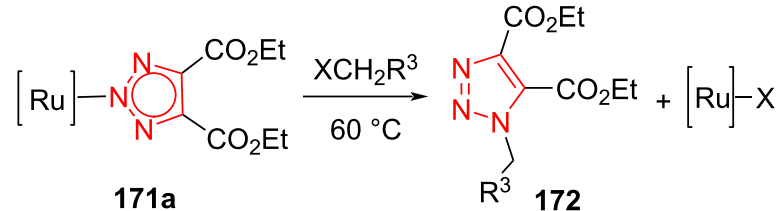

$$
\begin{aligned}
& 172 a=R^{3}=H, X=1 \\
& 172 b=R^{3}=C_{6} F_{5}, X=B r \\
& 172 \mathrm{c}=\mathrm{R}^{3}=\mathrm{Ph}, \mathrm{X}=\mathrm{Br} \\
& 172 \mathrm{~d}=\mathrm{R}^{3}=4-\mathrm{CNPh}, \mathrm{X}=\mathrm{Br} \\
& 172 \mathrm{c}=\mathrm{R}^{3}=4-\mathrm{CH}_{2} \mathrm{BrPh}, \mathrm{X}=\mathrm{Br}
\end{aligned}
$$


subsequently, final products were formed through a Ru-catalyzed azide-alkyne cycloaddition process. The current protocol tolerates a range of aromatic and aliphatic azides, affording a diverse range of 4-cyano-1,2,3-triazoles 175 (Scheme 46) [67].

\section{Ir-catalyzed synthesis of fully decorated triazoles}

A series of triazene-functionalized triazoles $\mathbf{1 8 2}$ was synthesized in moderate to high yield through an iridium-catalyzed, directing-group-promoted regioselective $[3+2]$-cycloaddition of alkynes $\mathbf{1 7 6}$ and azides 177. The optimized conditions for this reaction were found to be $\operatorname{Ir}(\operatorname{cod}) \mathrm{Cl}_{2}(2 \mathrm{~mol} \%)$ and $\mathrm{CH}_{2} \mathrm{Cl}_{2}$ at room temperature. The obtained triazoles $\mathbf{1 7 8}$ were then transformed into the corresponding 5-aminotriazoles 179 by reduction with Raney nickel in $\mathrm{MeOH}$ at $60{ }^{\circ} \mathrm{C}$. In addition, the further transformation of 5-aminotriazoles 179 into more complex derivatives, such as 180-183, was explored [68].

The Huisgen reaction of structurally diverse 1-alkynyltriazenes bearing 2-ClPh, 3-MePh, 4-FPh, and 4-MeOPh, respectively, with azides was explored (Scheme 47). In all cases, a high yield of the triazole derivative was obtained. The products can also be synthesized by alkynes bearing butyl, phenylethyl, cyclopropyl, and methoxymethyl moieties. Moreover, TMS-substituted alkyne was suitable for this Huisgen reaction to achieve the desired triazole product. Next, some triazene scaffolds, such as

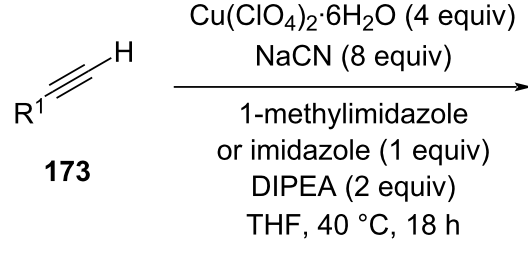

$\mathrm{THF}, 40^{\circ} \mathrm{C}, 18 \mathrm{~h}$

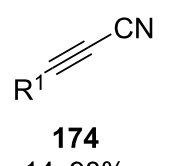

$14-98 \%$ $\mathrm{R}^{1}=$ aryl, alkyl

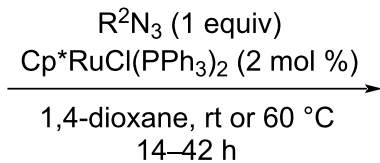<smiles>[R]c1c(C#N)nnn1[R]</smiles>

$40-92 \%$

Scheme 46: Synthesis of 4-cyano-1,2,3-triazoles 175

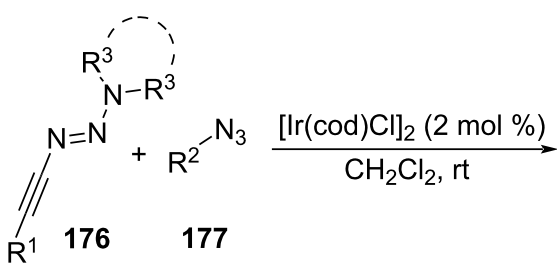

$\mathrm{R}^{1}=$ 2-CIPh, 3-MePh, 4-FPh, 4-MeOPh, thiophenyl, $\mathrm{CH}_{3}\left(\mathrm{CH}_{2}\right)_{3}, \mathrm{Ph}\left(\mathrm{CH}_{2}\right)_{2}$, cyclopropyl, $\mathrm{MeOCH}_{2}$, TMS, $\mathrm{Ph}$

$\mathrm{R}^{2}=\mathrm{Bn}, \mathrm{Ph}, 2-\mathrm{Ph}, 3-\mathrm{MePh}, 4-\mathrm{MeOPh}, 4-\mathrm{BrPh}$-naphthyl, $\mathrm{Ph}\left(\mathrm{CH}_{2}\right)_{2}$, cyclohexyl, $\mathrm{PhCHCHCH}, \mathrm{PhCC}\left(\mathrm{CH}_{2}\right)_{2}$, $\mathrm{PhCO}\left(\mathrm{CH}_{2}\right)_{3}, \mathrm{TsO}\left(\mathrm{CH}_{2}\right)_{2}$,<smiles>CC(C)(C)c1c[nH]c2ccccc12</smiles><smiles>CC(C)(C)CCOCCOCCOCCOS(C)(=O)=O</smiles><smiles>CC(C)(C)COC(=O)C([NH3+])[NH+](c1ccccc1)c1ccccc1</smiles>

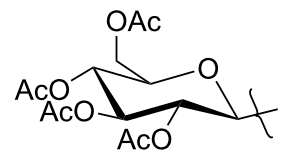<smiles></smiles>

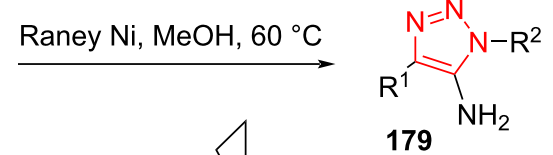

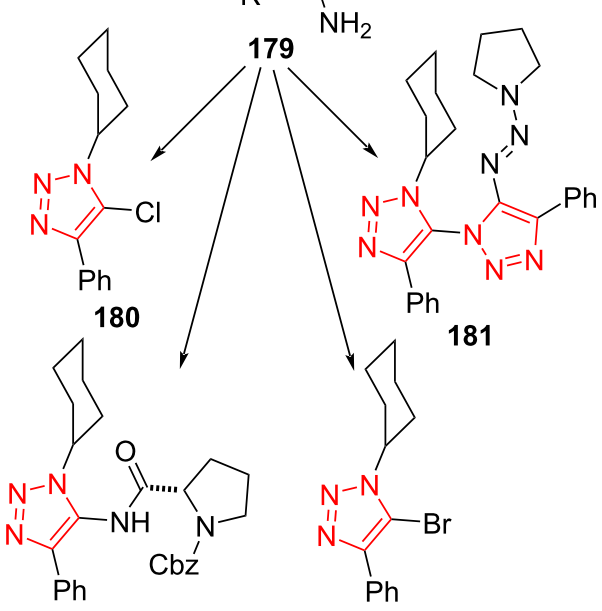

182

$\mathrm{R}^{3}=\mathrm{iPr}, \mathrm{Me}$,

time $=12 \mathrm{~h}$ yield $=78-98 \%$<smiles>CC1CCCCC1</smiles><smiles>CC1CCN(C(C)C)CC1</smiles>

183

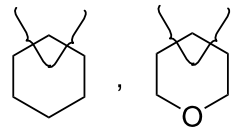


dimethylamino-, pyrrolidine-, piperidine-, morpholine-, and piperazine-derived triazenes were screened. Aryl azides containing $\mathrm{Br}, \mathrm{I}, \mathrm{Me}$, and $\mathrm{MeO}$ as well as 2-naphthyl azide have been used to give corresponding triazole derivatives efficiently under optimized reaction conditions. Alkyl azides containing functional groups including phenylethyl, indolyl, cyclohexyl, alkenyl, and alkynyl were suitable in this transformation to form the desired products. This method was then extended to ketone, tosyl, and phthalimide groups on alkyl azides to produce the desired triazole derivatives. The ethylene glycol-, phenylalanine-, and glucose-derived azides were also good candidates to furnish the triazole derivatives. This protocol provides access to various substituted triazoles under mild conditions starting from readily available starting materials, showing broad structural diversity (Scheme 47) [68].

The authors proposed a reasonable mechanism for this process. First, 1-alkyltriazene $\mathbf{1 7 6}$ and azide $\mathbf{1 7 7}$ are coordinated to the iridium center to form intermediate 184. Subsequently, oxidative coupling of the azide with the $\beta$-carbon atom of the 1-alkyltriazene gives the $\mathrm{Ir}$-carbene intermediate $\mathbf{1 8 5}$. In continuation, intermediate $\mathbf{1 8 5}$ can be transferred to intermediate 186, leading to the triazole ligand being coordinated to the Ir center in $\mathbf{1 8 7}$. Finally, the triazole product $\mathbf{1 7 8}$ is released and then, $\mathbf{1 7 6}$ and $\mathbf{1 7 7}$ are coordinated to the Ir center to enable a further catalytic run (Scheme 48) [68].

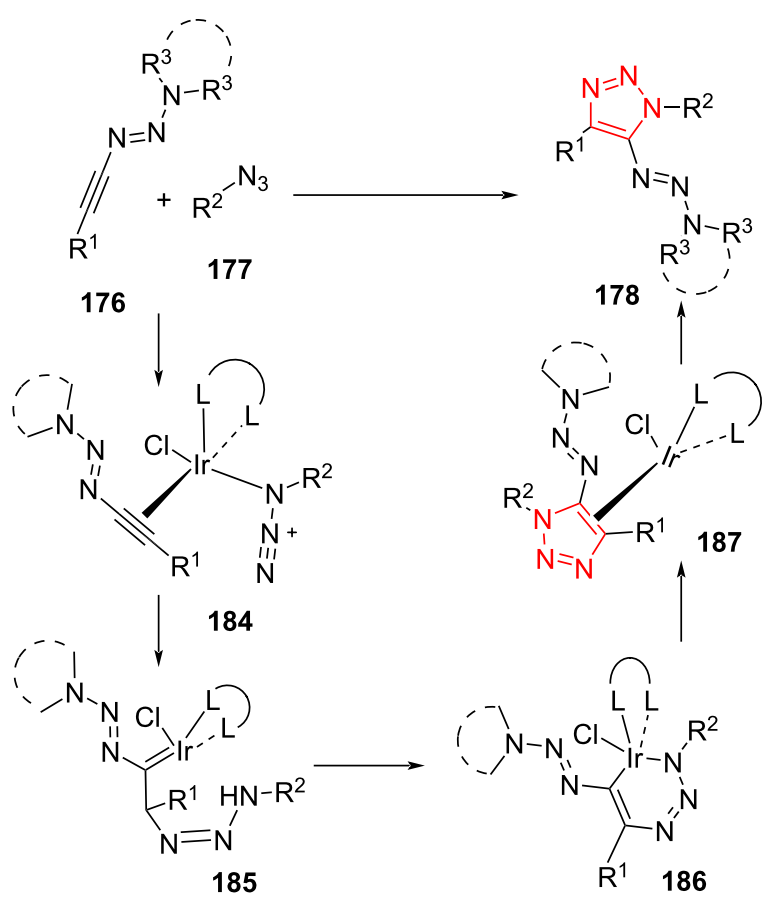

Scheme 48: Mechanism for the synthesis of functionalized triazoles from the reaction of 1-alkyltriazenes 176 and azides 177.

\section{Conclusion}

Over the last years, the synthesis of highly substituted triazoles has gained extensive interest. This is generally because of the diverse applications of these products in academia, pharmacy, and industry. This overview summarizes the latest advances in the synthesis of fully decorated triazoles. In many cases, the reaction mechanisms of triazole formation have been discussed. The current overview can serve as a base for future advancements in modern protocols for the preparation of new 1,4,5trisubstituted 1,2,3-triazoles with an extensive range of synthetic, biomedical, and materials applications.

\section{Funding}

We gratefully appreciate the Shiraz University of Medical Sciences Research Councils for the financial support of this work.

\section{ORCID ${ }^{\circledR}$ iDs}

Pezhman Shiri - https://orcid.org/0000-0003-0071-6570 Ali Mohammad Amani - https://orcid.org/0000-0002-7034-3071

\section{References}

1. Shiri, P. Mini-Rev. Med. Chem. 2021, 21, 536-553. doi:10.2174/1389557520666201027160436

2. Elattar, K. M.; El-Mekabaty, A. J. Heterocycl. Chem. 2021, 58, 389-414. doi:10.1002/jhet.4174

3. Alizadeh, A.; Roosta, A.; Rezaiyehrad, R.; Halvagar, M. Tetrahedron 2017, 73, 6706-6711. doi:10.1016/j.tet.2017.10.003

4. Alizadeh, A.; Roosta, A.; Halvagar, M. ChemistrySelect 2019, 4, 71-74 doi:10.1002/slct.201803418

5. Srinath, S.; Abinaya, R.; Prasanth, A.; Mariappan, M.; Sridhar, R.; Baskar, B. Green Chem. 2020, 22, 2575-2587. doi:10.1039/d0gc00569j

6. Zhang, X.; Li, X.; Li, J.-L.; Wang, Q.-W.; Zou, W.-L.; Liu, Y.-Q.; Jia, Z.-Q.; Peng, F.; Han, B. Chem. Sci. 2020, 11, 2888-2894. doi:10.1039/c9sc06377c

7. Maheshwari, K. K.; Bandyopadhyay, D. Curr. Med. Chem. 2021, 28, 472-495. doi:10.2174/0929867327666200219141652

8. Sharghi, H.; Shiri, P. Synthesis 2015, 47, 1131-1146. doi:10.1055/s-0034-1379951

9. Sharghi, H.; Shiri, P.; Aberi, M. Catal. Lett. 2017, 147, 2844-2862. doi:10.1007/s10562-017-2173-7

10. Fascio, M. L.; Errea, M. I.; D'Accorso, N. B. Eur. J. Med. Chem. 2015, 90, 666-683. doi:10.1016/j.ejmech.2014.12.012

11. Lelyukh, M.; Martynets, M.; Kalytovska, M.; Drapak, I.; Harkov, S.; Chaban, T.; Chaban, I.; Matiychuk, V. J. Appl. Pharm. Sci. 2020, 10, 151-165. doi:10.7324/japs.2020.1010016

12. Zhang, Y.-C.; Jiang, F.; Shi, F. Acc. Chem. Res. 2020, 53, 425-446. doi:10.1021/acs.accounts.9b00549

13. Pathania, S.; Narang, R. K.; Rawal, R. K. Eur. J. Med. Chem. 2019, 180, 486-508. doi:10.1016/j.ejmech.2019.07.043

14. Sharghi, H.; Aberi, M.; Shiri, P. Appl. Organomet. Chem. 2019, 33 , e4974. doi:10.1002/aoc.4974

15. Liu, L. L.; Zhou, J.; Cao, L. L.; Stephan, D. W. J. Am. Chem. Soc. 2019, 141, 16971-16982. doi:10.1021/jacs.9b09330 
16. Pawlowski, R.; Stanek, F.; Stodulski, M. Molecules 2019, 24, 1533. doi:10.3390/molecules24081533

17. Damale, M. G.; Pathan, S. K.; Shinde, D. B.; Patil, R. H.; Arote, R. B.; Sangshetti, J. N. Eur. J. Med. Chem. 2020, 207, 112712. doi:10.1016/j.ejmech.2020.112712

18. Mashayekh, K.; Shiri, P. ChemistrySelect 2019, 4, 13459-13478. doi:10.1002/slct.201902362

19. Feng, L.-S.; Zheng, M.-J.; Zhao, F.; Liu, D. Arch. Pharm. (Weinheim, Ger.) 2021, 354, e2000163. doi:10.1002/ardp.202000163

20. Batra, N.; Rajendran, V.; Agarwal, D.; Wadi, I.; Ghosh, P. C.; Gupta, R. D.; Nath, M. ChemistrySelect 2018, 3, 9790-9793. doi:10.1002/slct.201801905

21. Howieson, V. M.; Tran, E.; Hoegl, A.; Fam, H. L.; Fu, J.; Sivonen, K.; Li, X. X.; Auclair, K.; Saliba, K. J. Antimicrob. Agents Chemother. 2016, 60, 7146-7152. doi:10.1128/aac.01436-16

22. Gao, F.; Ye, L.; Kong, F.; Huang, G.; Xiao, J. Bioorg. Chem. 2019, 91, 103162. doi:10.1016/j.bioorg.2019.103162

23. Yang, C.-L.; Zhang, Y.-H.; Zi, Q.-X.; Lin, J.; Yan, S.-J. Preprints 2018, 2018070354. doi:10.20944/preprints201807.0354.v1

24. Kapkoti, D. S.; Singh, S.; Luqman, S.; Bhakuni, R. S. New J. Chem. 2018, 42, 5978-5995. doi:10.1039/c7nj04271j

25. Arroyo, S. Neurotherapeutics 2007, 4, 155-162. doi:10.1016/j.nurt.2006.11.006

26. Sierra, M. A.; de la Torre, M. C. ACS Omega 2019, 4, 12983-12994. doi:10.1021/acsomega.9b01285

27. Chen, Z.; Liu, Z.; Cao, G.; Li, H.; Ren, H. Adv. Synth. Catal. 2017, 359, 202-224. doi:10.1002/adsc.201600918

28. Şerban, G. Farmacia (Bucharest, Rom.) 2016, 64, 549-552.

29. Li, Z.; Wei, Q.; Song, L.; Han, W.; Wu, X.; Zhao, Y.; Xia, F.; Liu, S. Org. Lett. 2019, 21, 6413-6417. doi:10.1021/acs.orglett.9b02269

30. Jiang, Y.; Sun, R.; Tang, X.-Y.; Shi, M. Chem. - Eur. J. 2016, 22, 17910-17924. doi:10.1002/chem.201601703

31. Aboonajmi, J.; Sharghi, H.; Aberi, M.; Shiri, P. Eur. J. Org. Chem. 2020 5978-5984. doi:10.1002/ejoc.202000999

32. Shiri, P. Appl. Organomet. Chem. 2020, 34, e5600. doi:10.1002/aoc.5600

33. Gomes, R. S.; Jardim, G. A. M.; de Carvalho, R. L.; Araujo, M. H.; da Silva Júnior, E. N. Tetrahedron 2019, 75, 3697-3712. doi:10.1016/j.tet.2019.05.046

34. Neto, J. S. S.; Zeni, G. Coord. Chem. Rev. 2020, 409, 213217. doi:10.1016/j.ccr.2020.213217

35. Holm, S. C.; Straub, B. F. Org. Prep. Proced. Int. 2011, 43, 319-347. doi:10.1080/00304948.2011.593999

36. Shneine, J. K.; Alaraji, Y. H. Int. J. Sci. Res. 2016, 5, 1411-1423.

37. Moulin, A.; Bibian, M.; Blayo, A.-L.; El Habnouni, S.; Martinez, J.; Fehrentz, J.-A. Chem. Rev. 2010, 110, 1809-1827. doi:10.1021/cr900107r

38. Yang, M.; Yang, Y.; Chen, P. R. Top. Curr. Chem. 2016, 374, 2. doi:10.1007/s41061-015-0001-3

39. Zhang, D.; Fan, Y.; Yan, Z.; Nie, Y.; Xiong, X.; Gao, L. Green Chem. 2019, 21, 4211-4216. doi:10.1039/c9gc01129c

40. De Nino, A.; Algieri, V.; Tallarida, M. A.; Costanzo, P.; Pedrón, M.; Tejero, T.; Merino, P.; Maiuolo, L. Eur. J. Org. Chem. 2019, 5725-5731. doi:10.1002/ejoc.201900889

41. Guo, N.; Liu, X.; Xu, H.; Zhou, X.; Zhao, H. Org. Biomol. Chem. 2019, 17, 6148-6152. doi:10.1039/c9ob01156k

42. Deng, L.; Cao, X.; Liu, Y.; Wan, J.-P. J. Org. Chem. 2019, 84, 14179-14186. doi:10.1021/acs.joc.9b01817
43. Kundu, M.; Bhaumik, I.; Misra, A. K. Glycoconjugate J. 2019, 36, 439-450. doi:10.1007/s10719-019-09883-1

44. Silveira-Dorta, G.; Jana, S.; Borkova, L.; Thomas, J.; Dehaen, W. Org. Biomol. Chem. 2018, 16, 3168-3176. doi:10.1039/c8ob00533h

45. Ahamad, S.; Kumar, A.; Kant, R.; Mohanan, K. Asian J. Org. Chem. 2018, 7, 1698-1703. doi:10.1002/ajoc.201800340

46. Reddy, G. S.; Kumar, A. S.; Ramachary, D. B. Org. Biomol. Chem. 2020, 18, 4470-4478. doi:10.1039/d0ob00848f

47. Karsakova, I. V.; Smirnov, A. Y.; Baranov, M. S Chem. Heterocycl. Compd. 2018, 54, 755-757. doi:10.1007/s10593-018-2343-6

48. He, J.; Wang, W.; Zhou, H.; She, P.; Zhang, P.; Cao, Y.; Zhang, X. J. Drug Delivery Sci. Technol. 2019, 53, 101130. doi:10.1016/j.jddst.2019.101130

49. Li, K.; Fong, D.; Meichsner, E.; Adronov, A. Chem. - Eur. J. 2021, 27, 5057-5073. doi:10.1002/chem.202003386

50. Wu, F.; Zhou, W.; Chen, K.; Chen, W.; Liu, M.; Wu, H. Adv. Synth. Catal. 2018, 360, 2435-2439. doi:10.1002/adsc.201800394

51. Zhao, R.; Liao, Y.; Yan, T.; Cai, M. Appl. Organomet. Chem. 2020, 34, e5319. doi:10.1002/aoc.5319

52. Wang, W.; Huang, S.; Yan, S.; Sun, X.; Tung, C.-H.; Xu, Z. Chin. J. Chem. 2020, 38, 445-448. doi:10.1002/cjoc.201900556

53. Yamada, M.; Matsumura, M.; Takino, F.; Murata, Y.; Kurata, Y.; Kawahata, M.; Yamaguchi, K.; Kakusawa, N.; Yasuike, S. Eur. J. Org. Chem. 2018, 170-177. doi:10.1002/ejoc.201701389

54. Yamada, M.; Takahashi, T.; Hasegawa, M.; Matsumura, M.; Ono, K.; Fujimoto, R.; Kitamura, Y.; Murata, Y.; Kakusawa, N.; Tanaka, M.; Obata, T.; Fujiwara, Y.; Yasuike, S. Bioorg. Med. Chem. Lett. 2018, 28 , 152-154. doi:10.1016/j.bmcl.2017.11.038

55. Wang, W.; Lin, Y.; Ma, Y.; Tung, C.-H.; Xu, Z. Org. Lett. 2018, 20 , 2956-2959. doi:10.1021/acs.orglett.8b01002

56. Tatevosyan, S. S.; Kotovshchikov, Y. N.; Latyshev, G. V.; Erzunov, D. A.; Sokolova, D. V.; Beletskaya, I. P.; Lukashev, N. V. J. Org. Chem. 2020, 85, 7863-7876. doi:10.1021/acs.joc.0c00520

57. Jadhav, A. S.; Pankhade, Y. A.; Anand, R. V. J. Org. Chem. 2018, 83, 8596-8606. doi:10.1021/acs.joc.8b00573

58. Yu, X.; Xu, J.; Zhou, Y.; Song, Q. Org. Chem. Front. 2018, 5, 2463-2467. doi:10.1039/c8qo00590g

59. de Albuquerque, D. Y.; de Moraes, J. R.; Schwab, R. S. Eur. J. Org. Chem. 2019, 6673-6681. doi:10.1002/ejoc.201901249

60. Punzi, A.; Zappimbulso, N.; Farinola, G. M. Eur. J. Org. Chem. 2020, 3229-3234. doi:10.1002/ejoc.201901305

61. Veryser, C.; Steurs, G.; Van Meervelt, L.; De Borggraeve, W. M. Adv. Synth. Catal. 2017, 359, 1271-1276. doi:10.1002/adsc.201601388

62. Govdi, A. I.; Danilkina, N. A.; Ponomarev, A. V.; Balova, I. A. J. Org. Chem. 2019, 84, 1925-1940. doi:10.1021/acs.joc.8b02916

63. Saha, R.; Arunprasath, D.; Sekar, G. J. Catal. 2019, 377, 673-683. doi:10.1016/j.jcat.2019.07.063

64. Shiva Kumar, K.; Naikawadi, P. K.; Jatoth, R.; Dandela, R. Org. Biomol. Chem. 2019, 17, 7320-7324. doi:10.1039/c9ob01175g

65. Ferlin, F.; Yetra, S. R.; Warratz, S.; Vaccaro, L.; Ackermann, L. Chem. - Eur. J. 2019, 25, 11427-11431. doi:10.1002/chem.201902901

66. Chang, C.-W.; Lee, G.-H. J. Organomet. Chem. 2019, 896, 146-153. doi:10.1016/j.jorganchem.2019.06.013

67. Liu, P.; Clark, R. J.; Zhu, L. J. Org. Chem. 2018, 83, 5092-5103. doi:10.1021/acs.joc.8b00424

68. Zeng, L.; Lai, Z.; Zhang, C.; Xie, H.; Cui, S. Org. Lett. 2020, 22, 2220-2224. doi:10.1021/acs.orglett.0c00394 


\section{License and Terms}

This is an Open Access article under the terms of the Creative Commons Attribution License (https://creativecommons.org/licenses/by/4.0). Please note that the reuse, redistribution and reproduction in particular requires that the author(s) and source are credited and that individual graphics may be subject to special legal provisions.

The license is subject to the Beilstein Journal of Organic Chemistry terms and conditions:

(https://www.beilstein-journals.org/bjoc/terms)

The definitive version of this article is the electronic one which can be found at:

https://doi.org/10.3762/bjoc.17.114 